\title{
Methods Development for the Optical Determination of the Black Carbon Content of Loess Samples
}

\author{
Yan $\mathrm{Mu}^{1^{*}}$, Xiaoguang Qin1, Jiaqi Liu1, Zhiqiang Yin² \\ ${ }^{1}$ Institute of Geology and Geophysics, Chinese Academy of Sciences, Beijing, China \\ ${ }^{2}$ China Institute of Geo-Environment Monitoring, Beijing, China \\ Email: ${ }^{*}$ muyan@mail.iggcas.ac.cn
}

Received 12 February 2015; accepted 23 June 2015; published 29 June 2015

Copyright (C) 2015 by authors and Scientific Research Publishing Inc.

This work is licensed under the Creative Commons Attribution International License (CC BY). http://creativecommons.org/licenses/by/4.0/

(c) $\underset{\mathrm{EY}}{\mathrm{P}}$ Open Access

\begin{abstract}
We evaluate the applicability of an optical transmission measurement method commonly used for the analysis of the Black Carbon (BC) content of aerosol sample, to determine the $\mathrm{BC}$ content of loess sediments. A number of different sample pretreatment procedures are developed and compared, leading to an optimum preparation process. The results include: 1) Subtraction of the optical attenuation values before and after heating of the sample filters (" $\triangle A T N^{\prime \prime}$ ) varies linearly with the sample mass. The slope of the regression line provides the best determination of $\mathrm{BC}$ concentration. 2) When the sample mass is small, $\left(\mathrm{NaPO}_{3}\right)_{6}$ pretreatment is best for $\mathrm{BC}$ measurement, and the $\mathrm{BC}$ concentration results are given by the slope of the regression between $\triangle A T N$ and sample mass, for a series of samples of varying mass. 3) HF pretreatment accompanied by centrifugation and rinsing may produce a negative bias on the result. 4) Replicate measurements of $B C$ for loess samples showed a maximum deviation less than $5.6 \%$, suggesting that measurements of the $\mathrm{BC}$ concentration of a sequence of loess samples could determine variations to this degree of significance. 5) The overall trends of BC concentration in loess section sequences were similar for all chemical pretreatments. The $\mathrm{BC}$ concentration result for replicate samples is comparable when pretreated by the same procedure.
\end{abstract}

\section{Keywords}

Black Carbon, Optical Measurement Method, Loess Section, Pretreatment Procedure

\footnotetext{
${ }^{*}$ Corresponding author.
}

How to cite this paper: Mu, Y., Qin, X.G., Liu, J.Q. and Yin, Z.Q. (2015) Methods Development for the Optical Determination of the Black Carbon Content of Loess Samples. American Journal of Analytical Chemistry, 6, 585-603. 


\section{Introduction}

BC particles are ubiquitously present in our environment: both suspended as aerosols in the atmosphere, and in liquid and solid media after deposition to soils, loess, and aquatic sediments (both lacustrine and marine) [1]-[4]. There is an increasing realization of the potential importance of BC in many global processes [5] [6]. BC is a product of incomplete combustion of both fossil and contemporary (biomass) fuels, arising from combustion residues (e.g., charcoal) and condensed carbonaceous products [7] [8]. The continuum of properties from char and charcoal to soot particles does not have clear-cut boundaries [9], but the entire class of material is recognized to have large impacts on the global atmospheric carbon cycle and also provides a record of fire history [2] [7] [10]-[12]. Due to its inertness and thermal stability [5], BC transfers carbon from the rapid atmosphere-biosphere cycle into a much slower geological cycle. Consequently, it may represent a significant sink in the global carbon cycle [13]-[16]. BC may be considered as "missing carbon" providing sequestration in soils and sediments for thousands to millions of years [14] [17] [18]. However, quantitative estimates of the amount of BC in terrestrial and other environments are affected by uncertainty [2] [19]. BC values measured by different groups using different methods gave markedly different results [20] [21].

Various methods have been developed for the measurement of the BC content of samples [22]. These include optical, chemical, thermal [11] [23], thermal/optical [1], chemical-thermal oxidation (CTO) [7] [21] [24], thermal-optical reflectance (TOR) [25]-[32], spectroscopic and molecular marker analysis [33] [34], microscopy [2] [35] and others.

The methods most frequently used for the determination of the BC content of soil and sediment samples are the chemical, thermal, and chemical-thermal oxidation (CTO) methods, based on differences in the rates of degradation or oxidation between the BC and non-BC components [6]. However, the various oxidative methods have certain disadvantages for the analysis of soil and sediments. One major concern is that there is no standard means to verify the complete removal of the organic carbon (OC) content of the sample. Thermal or CTO methods which remove OC at elevated temperatures have the same limitations as chemical methods [36], in addition to the introduction of other interferences such as the "charring" of organic carbon, and oxidization of the BC component in an oxygen-rich environment [6]. Thus, different components of the "black carbon continuum" (from char to soot) in different matrices (soil, atmosphere, water, sediments) may be incorrectly analyzed by these methods [22].

The removal of carbonates by chemical pretreatment is used in most oxidative methods. Removal of silicate by a mixture of $\mathrm{HCl}$ and $\mathrm{HF}$ was also used in the TOR method [29]-[32] [37]. Han et al. and Gustafsson et al. pointed out that $\mathrm{HCl}$ pretreatment could lead to a substantial negative interference underestimation due to HCl-promoted oxidation of soot particles at high temperatures[21] [32].

For aerosol samples, BC is quantitatively measured by optical methods, and this analytical technique is based upon a determination of the "Attenuation” i.e. "blackness".

The Optical Transmission analytical method is rapid, non-contact, non-contaminating and non-destructive. Now both OT-21 and Aethalometer which is a real-time BC optical measurement instrument are widely used to measure BC content of aerosol samples in worldwide [25] [38].

This optical method to measure BC content by using OT-21, was developed in 1993 [39]. Ahmed et al. compared the measured BC results of OT-21 with that of thermal/optical method [1]. They demonstrated that the positive correlation between the results of two methods was good. The thermal/optical method has been widely used to measure BC content and accepted by most scientists now. Therefore, the optical measurement method of BC has been approved to be usable.

It is commonly used for the analysis of the BC content of aerosol samples collected on quartz filters [1]. However, there have been few studies of the BC content of soil and sediment samples by the optical methods other than TOR.

It is known that the periodic variability of the composition of loess-paleosol sequences reflects changes between dry and wet periods [40]; and the concentration of BC reflects changes similar to climatic fluctuations [41].

The purpose of this study was to investigate rapid, convenient and quantitative methods to measure the BC content of loess samples. This work establishes the optimum experimental procedures and improves a measurement method. We also evaluate carefully the effect of different pretreatment procedures on the results of the BC measurement of sediment samples. 


\section{Samples}

The loess and paleosol samples used in this study were taken from a loess-paleosol section located at $\left(34^{\circ} 34^{\prime} \mathrm{N}\right.$, $109^{\circ} 32^{\prime} \mathrm{E}$ ) near Yangge town, Weinan, in Shanxi province in the southern Chinese Loess Plateau. This section has been studied extensively [42]-[44]. Five samples were selected from the loess and paleosol formation units respectively, as shown in Table 1, in order to develop a measurement method that could distinguish the differences of BC concentration between loess samples formed under different climatic conditions.

\section{Methods}

In this study, we employed the BC measurement method using Optical Transmission analysis described by Ahmed et al. (2009). We used the same Optical Transmissometer (Model OT-21, Magee Scientific, California USA) as is commonly used in atmospheric aerosol research [1].

The OT-21 has a movable tray with two locations for holding filters. The outer position is used for the sample, while the inner position holds the reference (blank filter). The instrument compares the intensity of 880-nm light transmitted through the sample, to the intensity transmitted through the reference blank filter. The "Attenuation" $(A T N)$ is defined as:

$$
A T N=100 \times \ln \left(I_{0} / I\right)
$$

where $I$ and $I_{0}$ are the intensities transmitted through the sample and blank filters respectively.

The Attenuation is related to the surface loading density of BC by the relation

$$
A T N=B C \times \sigma
$$

where the $\mathrm{BC}$ density (in units of $\mu \mathrm{g} \cdot \mathrm{cm}^{-2}$ ) is determined by dividing ATN by the "Specific Attenuation" coefficient $\sigma$. The usual value of $\sigma$ recommended by the instrument manufacturer is $16.6 \mathrm{~cm}^{2} \cdot \mu \mathrm{g}^{-1}$ for the analysis at $880 \mathrm{~nm}$ of samples collected on quartz fiber filters. The BC density is then converted to a BC concentration fraction by mass.

Specific methods-development steps were required in order to apply this technique to the analysis of sediment samples. These were: 1) to weigh a sequence of different masses for each sample; 2) to pre-treat the samples by seven different procedures for removal of carbonate, OC and silicate; 3) to collect the samples by filtration onto quartz-fiber filters; and 4) to measure the BC content. These procedures are described in detail in the following sections.

\subsection{Weighing of Sample Masses}

Previous studies show that the BC content of loess is generally low, in the range of $0.010 \%-0.054 \%$ (Han et al., 2007), and $0.041 \%-0.572 \%$ (Wang et al., 2005). Thus, the BC content of samples may be below detection limits for small sample masses. However, too large a sample mass may result in an inaccurate measurement of BC content if the sample filter is too dark to be measured by optical methods, or if grains of the sample drop off from the filter.

Before the samples were weighed, all soils were lightly ground with an agate mortar in order to remove adhesion aggregates and to mix the samples uniformly. Aliquots of $5 \mathrm{mg}, 10 \mathrm{mg}, 15 \mathrm{mg}, 20 \mathrm{mg}$ and $25 \mathrm{mg}$ were weighed out for each sample (Table 2) and put into $50 \mathrm{ml}$ polypropylene tubes for subsequent pretreatments.

\subsection{Pretreatment Procedures}

In loess samples, there are three forms of carbon: BC (or elemental carbon); OC; and carbonate. Various pretreatment procedures were used to remove carbonate and OC from loess samples. Following the methods of other authors [21] [24] [29]-[32], 2N hydrochloric acid ( $\mathrm{HCl})$ was added to the tubes to remove carbonate; while OC was removed by adding oxidants [11]. In this study, because the expected mass of BC was small, it was necessary to allow at least 24 hrs for complete removal of carbonate and OC.

Seven pretreatment procedures were designed for use in this study. In all procedures except the HF pretreatment, approximately $3 \mathrm{ml}$ of $\left(\mathrm{NaPO}_{3}\right)_{6}$ was added as a dispersant (Table 2), and the OC removal was finished at $140^{\circ} \mathrm{C}$.

(1) “ $\left(\mathrm{NaPO}_{3}\right)_{6}$ pretreatment”: Add 30\% $\left(\mathrm{NaPO}_{3}\right)_{6}$ as dispersant

This pretreatment was intended to disperse any cemented aggregates in the loess samples. Approximately $10 \mathrm{ml}$ 
Table 1. Samples from different loess-paleosol formations.

\begin{tabular}{ccl}
\hline Sample location & Sample number & \multicolumn{1}{c}{ loess-paleosol formation units } \\
\hline & WN05-I-A-32 & Paleosol of Holocene Optimal, $\mathrm{S}_{0}$, i.e. Marine isotopic stage-1(MIS-1) \\
WN05-I-A-103 & Loess of the last glacial maximum (LGM), $\mathrm{L}_{1-1}$, i.e. Marine isotopic stage-2 (MIS-2) \\
Weinan & WN05-II-A-8 & Weakly-developed paleosol of the last glacial period, $\mathrm{L}_{1-2}$, i.e. Marine isotopic stage-3 (MIS-3) \\
& WN05-III-A-24 & Loess of the last glacial period, $\mathrm{L}_{1-5}$, i.e. Marine isotopic stage-4 (MIS-4) \\
& WN05-IV-A-6 & Paleosol of the last interglacial period, $\mathrm{S}_{1}$, i.e. Marine isotopic stage-5 (MIS-5) \\
\hline
\end{tabular}

Table 2. Weighed sample mass and pretreatment procedures for each loess sample.

\begin{tabular}{|c|c|c|c|c|c|c|}
\hline \multirow{2}{*}{$\begin{array}{c}\text { Procedures } \\
1\end{array}$} & \multicolumn{5}{|c|}{ Sample mass (mg) } & \multirow[t]{2}{*}{ Pretreatments $^{\mathrm{a}}$} \\
\hline & 5 & 10 & 15 & 20 & 25 & \\
\hline 2 & 5 & 10 & 15 & 20 & 25 & 1) 2 N HCl; 2) dispersant \\
\hline 3 & 5 & 10 & 15 & 20 & 25 & 1) $30 \% \mathrm{H}_{2} \mathrm{O}_{2}$; 2)dispersant \\
\hline 4 & 5 & 10 & 15 & 20 & 25 & 1) $2 \mathrm{~N} \mathrm{HCl}$; 2) $30 \% \mathrm{H}_{2} \mathrm{O}_{2}$; 3) dispersant \\
\hline 5 & 5 & 10 & 15 & 20 & 25 & 1) $30 \% \mathrm{H}_{2} \mathrm{O}_{2}$; 2) $2 \mathrm{~N} \mathrm{HCl}$; 3) dispersant \\
\hline 6 & 10 & 15 & 20 & 25 & $200^{\mathrm{b}}$ & 1) $2 \mathrm{~N} \mathrm{HCl}$; 2) $48 \% \mathrm{HF}$ \\
\hline 7 & 10 & 15 & 20 & 25 & 200 & 1) $2 \mathrm{~N} \mathrm{HCl}$; 2) $30 \% \mathrm{H}_{2} \mathrm{O}_{2}$; 3) $48 \% \mathrm{HF}$ \\
\hline
\end{tabular}

${ }^{\mathrm{a}}$ Acid treatment and $\mathrm{H}_{2} \mathrm{O}_{2}$ treatment in all procedures were similar and waited for 24 hrs to ensure that the reaction could run to completion. ${ }^{\mathrm{b}}$ In HF-added pretreatments, $200 \mathrm{mg}$ mass of samples follows the former work of Wang et al. (2005) [41].

of de-ionized water was put into the tubes with the weighed samples, and then $\sim 3 \mathrm{ml}$ of $\left(\mathrm{NaPO}_{3}\right)_{6}$ were added. The tubes were shaken lightly to mix the sample uniformly, and then kept at room temperature for at least $24 \mathrm{hrs}$.

(2) "HCl pretreatment": Add 2N HCl for carbonate removal

The samples were digested in $3-10 \mathrm{ml}$ of $2 \mathrm{~N}$ hydrochloric acid $(\mathrm{HCl})$ at room temperature for at least $24 \mathrm{hrs}$ to remove carbonates.

(3) " $\mathrm{H}_{2} \mathrm{O}_{2}$ pretreatment": Add $30 \% \mathrm{H}_{2} \mathrm{O}_{2}$ for OC removal

The samples were digested in $3-5 \mathrm{ml}$ of $30 \% \mathrm{H}_{2} \mathrm{O}_{2}$ at $140^{\circ} \mathrm{C}$. After the bubble of OC reaction disappeared, the residues were laid at room temperature for at least 24 hrs to remove OC completely.

(4) " $\mathrm{HCl}+\mathrm{H}_{2} \mathrm{O}_{2}$ pretreatment": Add $2 \mathrm{~N} \mathrm{HCl}$ and then $30 \% \mathrm{H}_{2} \mathrm{O}_{2}$

The samples were first digested in $3-10 \mathrm{ml}$ of $2 \mathrm{~N} \mathrm{HCl}$ at room temperature for at least $24 \mathrm{hrs}$ to remove carbonates. Then, OC removal was under the same condition as procedure (3).

(5) “ $\mathrm{H}_{2} \mathrm{O}_{2}+\mathrm{HCl}$ pretreatment”: Add $30 \% \mathrm{H}_{2} \mathrm{O}_{2}$ and then $2 \mathrm{~N} \mathrm{HCl}$

OC removal was under the same condition as procedure (3). Then, 3 - $10 \mathrm{ml}$ of $2 \mathrm{~N} \mathrm{HCl}$ was added to remove carbonates under the same conditions.

(6) “ $\mathrm{HCl}+\mathrm{HF}$ pretreatment”: Add $2 \mathrm{~N} \mathrm{HCl}$ and then $48 \% \mathrm{HF}$

The samples were first digested in $3-10 \mathrm{ml}$ of $2 \mathrm{~N} \mathrm{HCl}$ at room temperature for at least 24 hrs to remove carbonates. Next, 10 - $15 \mathrm{ml}$ of 48\% HF: $2 \mathrm{~N} \mathrm{HCl} \mathrm{(1:1} \mathrm{mixture)} \mathrm{was} \mathrm{added} \mathrm{for} \mathrm{another} 24$ hrs to remove silicates. Finally, the residues were separated from the supernatant by centrifugation (3500 rpm for $10 \mathrm{~min}$ ) and rinsed with de-ionized water 3 or 4 times until neutral.

(7) " $\mathrm{HCl}+\mathrm{H}_{2} \mathrm{O}_{2}+\mathrm{HF}$ pretreatment": Add $2 \mathrm{~N} \mathrm{HCl}$, then $30 \% \mathrm{H}_{2} \mathrm{O}_{2}$ and finally $48 \% \mathrm{HF}: 2 \mathrm{~N} \mathrm{HCl}$ mixture

After $\mathrm{HCl}$ and $\mathrm{H}_{2} \mathrm{O}_{2}$ pretreatment as described in (4) above, add $\mathrm{HF}$ as in (6) above.

Before being used for sample collection, the blank quartz filters (of $47 \mathrm{~mm}$ diameter) were heated in a muffle furnace at $850^{\circ} \mathrm{C}$ for $3 \mathrm{hrs}$ to remove any adsorbed organic vapors or previous $\mathrm{BC}$ content.

After the pretreatments described above, the sample residues were moved to $500 \mathrm{ml}$ quartz beakers, diluted with $200 \mathrm{ml}$ of de-ionized water, and then drawn through the pre-fired quartz fiber filters. These loaded filters were placed on clean tinfoil and were dried in an oven at $50^{\circ} \mathrm{C}$ for at least $12 \mathrm{hrs}$. All final samples for analysis were kept in individual sample boxes and stored in a refrigerator before optical analysis.

\subsection{Optical Method for BC Measurement of Soil and Sediments}

In loess sediments, there are various minerals that may influence the absorption of light at $880 \mathrm{~nm}$ passing through the sample filters. It is necessary to consider the contribution of both the $\mathrm{BC}$ and the mineral content to 
the attenuation of transmitted light. The optical attenuation of sample filter is [39]:

$$
A T N_{1}=\sigma_{\mathrm{BC}} \times[\mathrm{BC}]+\sigma_{\text {mineral } 1} \times[\text { mineral }]
$$

where $[\mathrm{BC}]$ represents the mass per unit area of black carbon in the sample on the filter, $\sigma_{\text {mineral } 1}$ represents the specific attenuation coefficient of the mineral content in its initial form, and [mineral] represents the mass per unit area of mineral compounds on the filter.

After heating to a high temperature in an oxygen-containing atmosphere, any BC in the sample will be completely burned away [45]. However, the mineral (which is refractory) will remain, although its efficiency for absorbing light may be changed. Consequently, the optical attenuation of the sample after heating will be

$$
A T N_{2}=\sigma_{\text {mineral } 2} \times[\text { mineral }]
$$

where $\sigma_{\text {mineral } 2}$ is the specific attenuation coefficient of the mineral content after heating; and which may be different from $\sigma_{\text {mineral } 1}$.

The difference of the two measured $A T N$ values $(\triangle A T N)$ can be used to determine the $\mathrm{BC}$ concentration of the samples.

$$
\begin{aligned}
& \Delta A T N=\sigma_{\mathrm{BC}} \times[\mathrm{BC}]+\left(\sigma_{\text {mineral } 1}-\sigma_{\text {mineral } 2}\right) \times[\text { mineral }] \\
& \Delta A T N=\sigma_{\mathrm{BC}} \times[\mathrm{BC}]+\Delta \sigma_{\text {mineral }} \times[\text { mineral }]=m \times\left(\sigma_{\mathrm{BC}} \times a+\Delta \sigma_{\text {mineral }} \times b\right)
\end{aligned}
$$

where $\Delta \sigma_{\text {mineral }}=\sigma_{\text {mineral } 1}-\sigma_{\text {mineral } 2}$ represents the change in specific attenuation coefficient of the mineral content after heating. " $m$ " is the sample mass. The parameters $a$ and $b$ is the content (\%) of Black Carbon and minerals in the sample and $a+b=1$. Thus, [BC] $=a \times m$ and [mineral] $=a \times m$.

This method was firstly developed by Hansen et al to eliminate the effect of dust on BC measurement of aerosol samples [39]. He also considered that the result $\mathrm{BC}_{1}$ of the before-heated sample filter measured by OT-21 is the combination of real $\mathrm{BC}$ and dust. The result $\mathrm{BC}_{2}$ of the after-heated $\left(850^{\circ} \mathrm{C}\right)$ sample filter measured by OT-21 is only the effect of dust because both $\mathrm{BC}$ and $\mathrm{OC}$ were oxidized at $850^{\circ} \mathrm{C}$. Thus, real $\mathrm{BC}$ content should be their subtraction $\mathrm{BC}=\mathrm{BC}_{1}-\mathrm{BC}_{2}$. Our progress was the improvement of optical method for $\mathrm{BC}$ measurement of dust aerosol samples, because Hansen et al didn't considered that the minerals of dust might be changed due to heating [39]. For example, the minerals on the filter become a little bit red after heated. It may be due to the alternation from $\mathrm{Fe}^{2+}$-minerals to $\mathrm{Fe}^{3+}$-minerals.

\section{Results}

\subsection{Evaluation of Precision and Repeatability}

Before measuring BC content, it was necessary to investigate the repeatability of the OT-21 instrument in terms of the deviation in measurements between repetitive placements of a given sample filter, and the deviation in measurements of several replicates of the same sample.

\subsubsection{Repeatability and Deviation during Repetitive Placements of a Filter}

Five sample filters (ME4-46, ME4-47, ME4-48, ME4-49, and ME4-50) were derived from a specific paleosol $\mathrm{S}_{0}$ sample (WN05-I-A-32). The sample mass was about $20 \mathrm{mg}$, and the " $\mathrm{HCl}+\mathrm{H}_{2} \mathrm{O}_{2}$ pretreatment" (procedure 4) was used.

Precision Analysis (1): Repeatability of OT-21 instrument.

The five sample filters were measured identically. Each was analyzed 5 times in succession to calculate the average measurement value (mean) and the standard deviation (SD). The deviation represented the repeatability of measurement by the OT-21 instrument.

Precision Analysis (2): Deviation in measurement of repetitive placements of a given sample.

Each sample filter after heating was analyzed multiple times by repetitive placement in the OT-21. After each sample was measured, it was taken out, and then put back in again; and the next measurement was performed. Each filter was tested 5 times and the mean and SD were calculated (Table 3). This process checked the effect of multiple placements on the reproducibility of the measurement value.

Table 3 summarizes the results of the two precision analysis processes. For Precision Analysis (1), the measurement value $A T N$ of a sample filter changes slightly and yields a low S/M ratio. The maximum S/M ratio was 
Table 3. Results and deviations of repetitive measurements of sample filters.

\begin{tabular}{|c|c|c|c|c|c|c|c|c|}
\hline \multirow{2}{*}{ Sample filter } & \multirow{2}{*}{ Mass (mg) } & \multicolumn{3}{|c|}{ Precise analysis (1) } & \multicolumn{3}{|c|}{ Precise analysis (2) } & \multirow{2}{*}{$\mathrm{BC}\left(\mathrm{ng} \cdot \mathrm{mg}^{-1}\right)$} \\
\hline & & STD & Mean (ng. $\mathrm{mg}^{-1}$ ) & $\mathrm{S} / \mathrm{M}(\%)^{\mathrm{a}}$ & STD & Mean (ng.mg ${ }^{-1}$ ) & $\mathrm{S} / \mathrm{M}(\%)$ & \\
\hline ME4-46 & 20.27 & 3.88 & 550 & 0.70 & 5.09 & 270 & 1.88 & 280 \\
\hline ME4-47 & 20.11 & 1.87 & 479 & 0.39 & 2.70 & 229 & 1.18 & 250 \\
\hline ME4-48 & 20.23 & 1.45 & 611 & 0.24 & 3.39 & 332 & 1.02 & 279 \\
\hline ME4-49 & 20.32 & 2.31 & 527 & 0.44 & 5.12 & 266 & 1.92 & 261 \\
\hline \multirow[t]{2}{*}{ ME4-50 } & 20.23 & 1.57 & 467 & 0.34 & 9.40 & 211 & 4.45 & 256 \\
\hline & & & & & & & & $\begin{array}{c}\text { Mean }=265 \\
\text { STD }=13.6 \\
\text { S/M }=5.14 \%\end{array}$ \\
\hline
\end{tabular}

${ }^{\mathrm{a}} \mathrm{S} / \mathrm{M}(\%)=100 \times \mathrm{STD} /$ mean. It represented the precise of measurement.

$0.70 \%$ and the minimum was $0.24 \%$. For Precision Analysis (2), the S/M ratio was the order of $1.02 \%-4.45 \%$ (Table 3), normally less than $2 \%$ and only reaching $4.45 \%$ once. This means that the replicative placement of a filter does influence the measurement result of the OT-21. The influence was limited within a narrow range $(<2 \%)$ for loess samples in most cases.

\subsubsection{Measurement Deviation of Multiple Replicates of the Same Sample}

For multiple replicates, the $\mathrm{SD}$ of $\triangle A T N$ was 0.47 . The $\mathrm{S} / \mathrm{M}$ ratio suggests a measurement precision of $5.6 \%$ (Table 3).

For five replicates of the same sample, the mineral composition and grain size should be identical. Thus, the positive value of the measured $\triangle A T N$ might result from the slight difference of $B C$ distribution, or changes in the mineral properties after heating the samples on these quartz filters. Indeed, Schmidt et al. found that the BC concentration measured for individual soil samples varied over 2 orders of magnitude in multiple measurements [20]. The measurement precision found in this study is far higher than that.

\subsection{BC Measurement Results}

4.2.1. Results of BC Measurement Assuming No Change in Mineral Optical Properties after Heating Whether or not the mineral content changes its optical properties after heating, is a central issue. If we use the assumption that the absorption of light at $880 \mathrm{~nm}$ by the mineral content of the sample is unchanged by heating, we may represent this as $\sigma_{\text {mineral } 1}=\sigma_{\text {mineral } 2}$. Thus, based on Equation (5), $\triangle A T N$ can be used to calculate the BC concentration directly [39].

$$
\triangle \mathrm{ATN}=\sigma_{\mathrm{BC}} \times[\mathrm{BC}]
$$

Results of BC measurements using this assumption are shown in Figure 1. For each sample, the overall BC value trends associated with increasing mass are similar for different pretreatments, although the absolute BC values obtained using different pretreatments may be different. In addition, the BC value trend was different for different samples. This implies that the property of the samples may influence the BC value with increasing mass. For all samples, when the sample mass was less than $10 \mathrm{mg}$, the fluctuation trends of the measured values were larger than those obtained with larger sample masses.

It is noticeable that some measured BC values, especially those obtained using HF pretreatment, were smaller than zero (Figures 1(a)-(d)). This indicates that the measured value of ATN for a sample filter after heating is larger than before heating.

Comparison between different pretreatment procedures

The BC values measured for samples undergoing the seven different pretreatments were compared with each other in order to reveal the possible effects of differing pretreatment procedures on the BC result.

1) Comparison between " $\left(\mathrm{NaPO}_{3}\right)_{6}$ pretreatment" and " $\mathrm{HCl}$ pretreatment"

In most cases, the measured $\mathrm{BC}$ value of samples given pretreatment procedure 1 (adding $\left(\mathrm{NaPO}_{3}\right)_{6}$ as dispersant) is a little larger than those given procedure 2 (adding $\mathrm{HCl}$ for carbonate removal), as shown in Figure 2. 


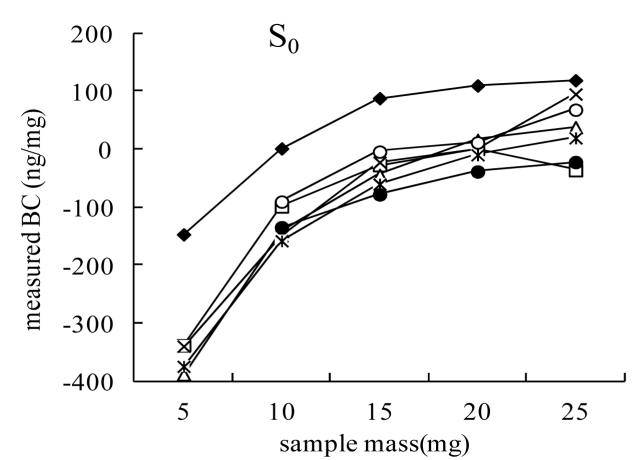

(a)

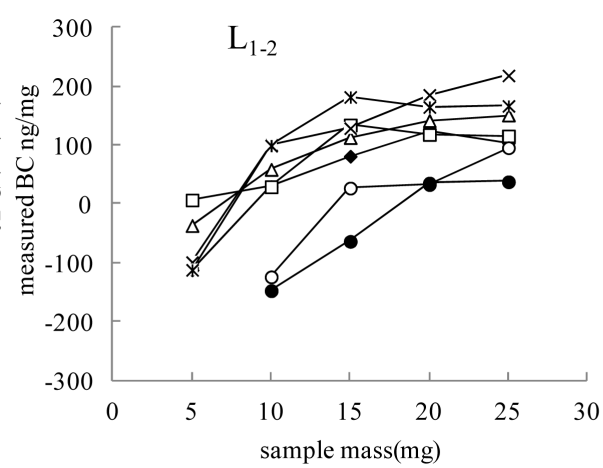

(c)

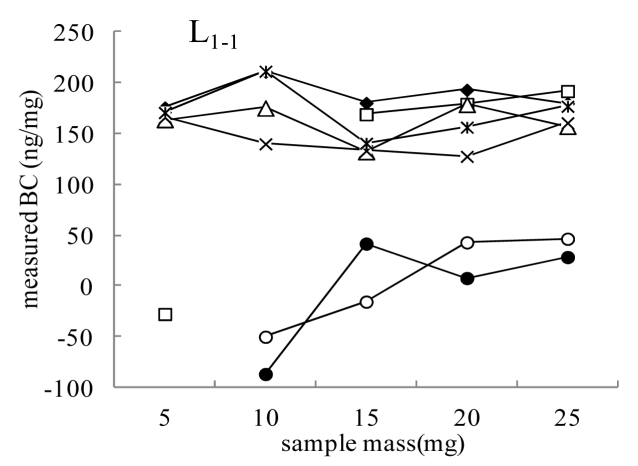

(b)

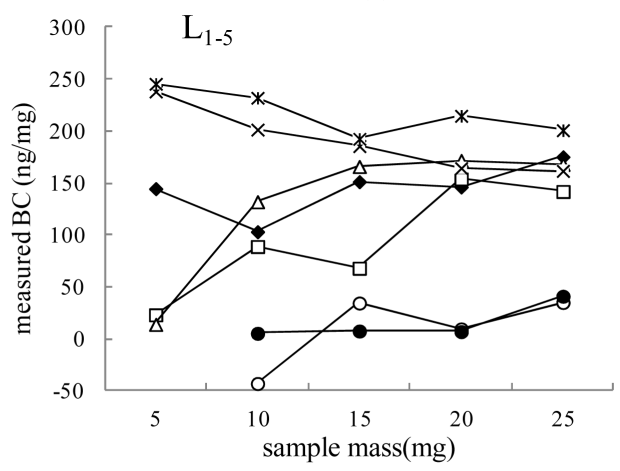

(d)

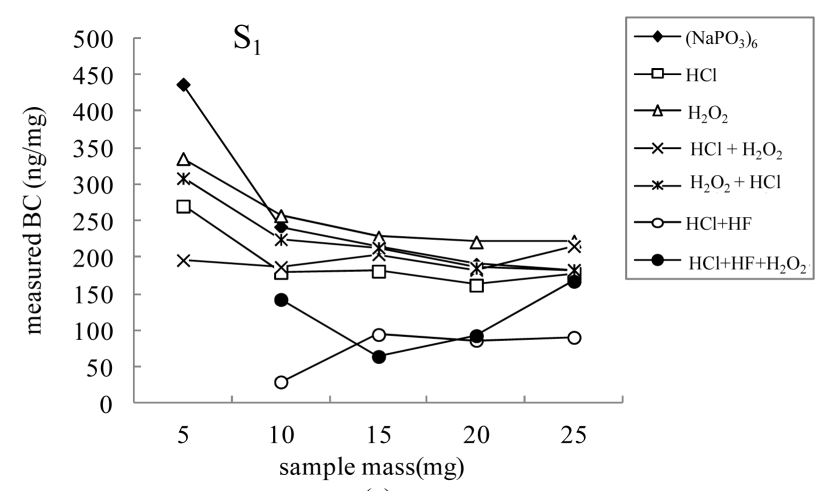

(e)

\section{Figure 1. Measured BC concentration results for increasing sample mass.}

2) Comparison between " $\mathrm{HCl}$ pretreatment" and " $\mathrm{HCl}+\mathrm{H}_{2} \mathrm{O}_{2}$ pretreatment"

Most of the results obtained using pretreatment procedure 2 (adding $\mathrm{HCl}$ ) are lower than those obtained using pretreatment procedure 4 (adding $\mathrm{HCl}+\mathrm{H}_{2} \mathrm{O}_{2}$ to remove carbonate and OC), as shown in Figure 3.

Similar to the above situation (2), the BC results using pretreatment procedure 2 were higher than those using procedure 4 for the $\mathrm{L}_{1-1}$ sample.

3) Comparison between " $\left(\mathrm{NaPO}_{3}\right)_{6}$ pretreatment" and "HF acid pretreatment"

The result obtained using pretreatment procedure 1 were compared with those using procedure 7 (adding $\mathrm{HCl}$ $+\mathrm{H}_{2} \mathrm{O}_{2}+\mathrm{HF}$ ) with OC removal, and procedure 6 (adding $\mathrm{HCl}+\mathrm{HF}$ ) without OC removal. Most of the BC measurements using procedure 1 are far greater than those using either HF procedure, as shown in Figure 4 . The results of the two HF pretreatments are similar.

4) Comparison between "HCl pretreatment" and "HF pretreatments"

In order to analyze the effect of acid pretreatments on measurements of the BC content of sediments, the result of the $\mathrm{HCl}$ pretreatment was compared with that of the HF pretreatments, as shown in Figure 5. In general, the results using $\mathrm{HCl}$ pretreatment are larger than those obtained using HF pretreatment for most samples, except 


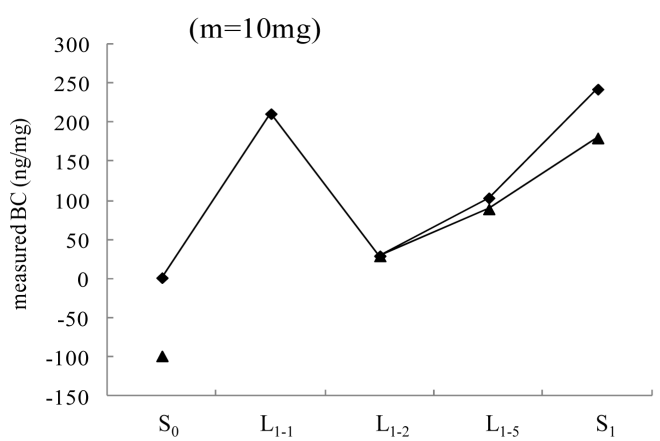

(a)

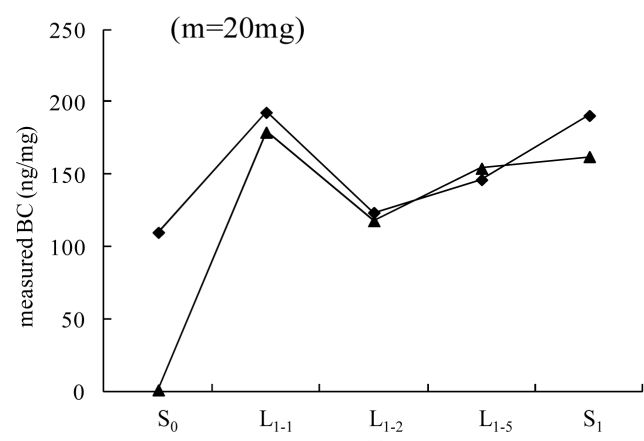

(c)

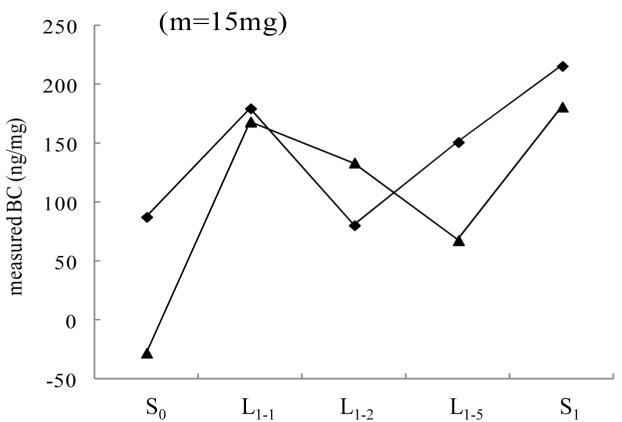

(b)

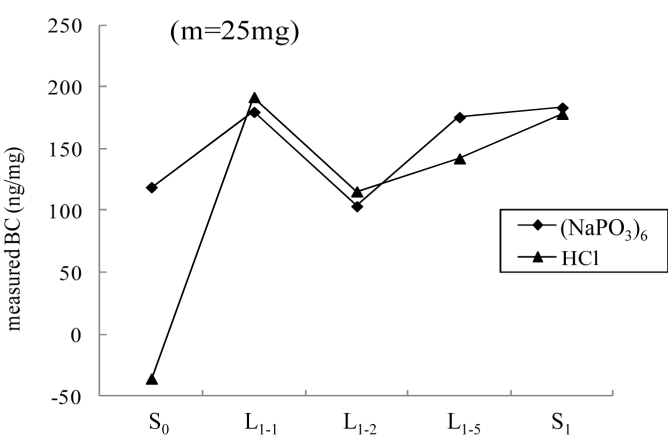

(d)

Figure 2. Comparison between $\left(\mathrm{NaPO}_{3}\right)_{6}$ pretreatment and $\mathrm{HCl}$ acid pretreatment.

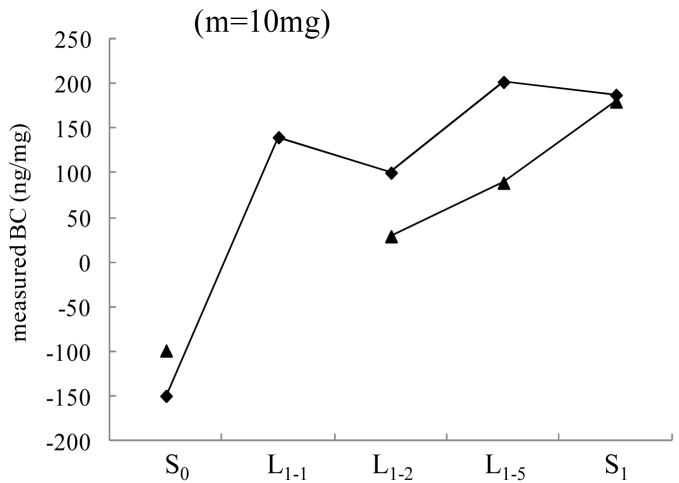

(a)

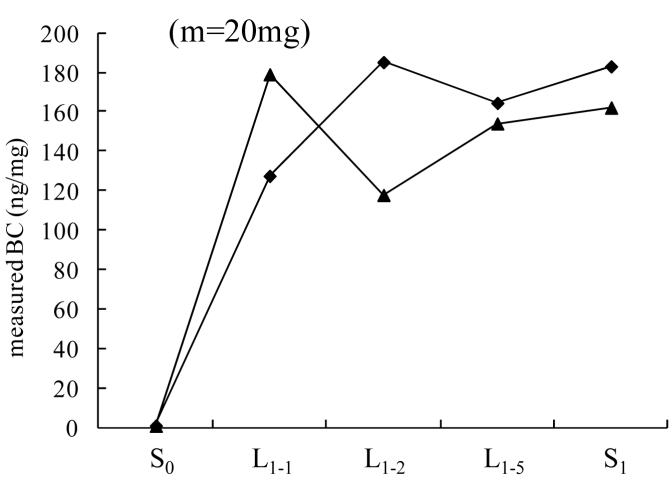

(c)

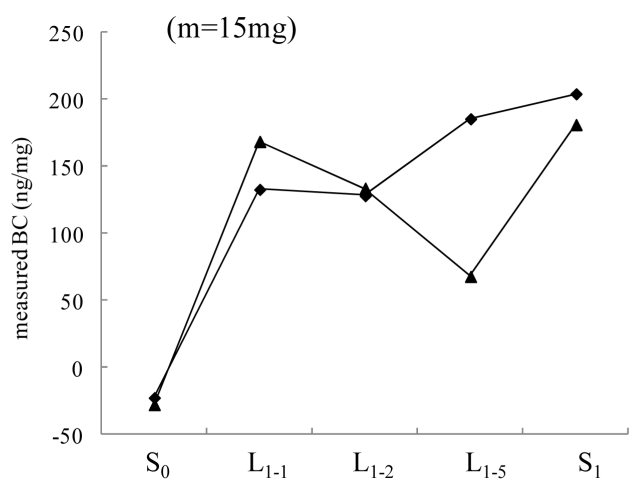

(b)

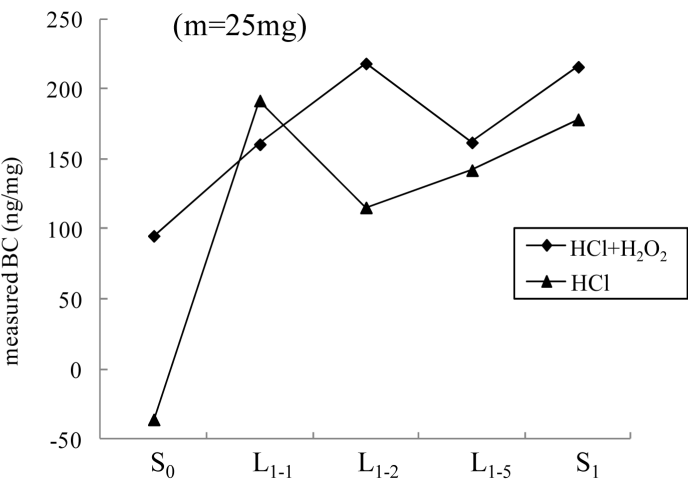

(d)

Figure 3. Comparison between results obtained with " $\mathrm{HCl}$ pretreatment" and " $\mathrm{HCl}+\mathrm{H}_{2} \mathrm{O}_{2}$ pretreatment" for different samples masses. 

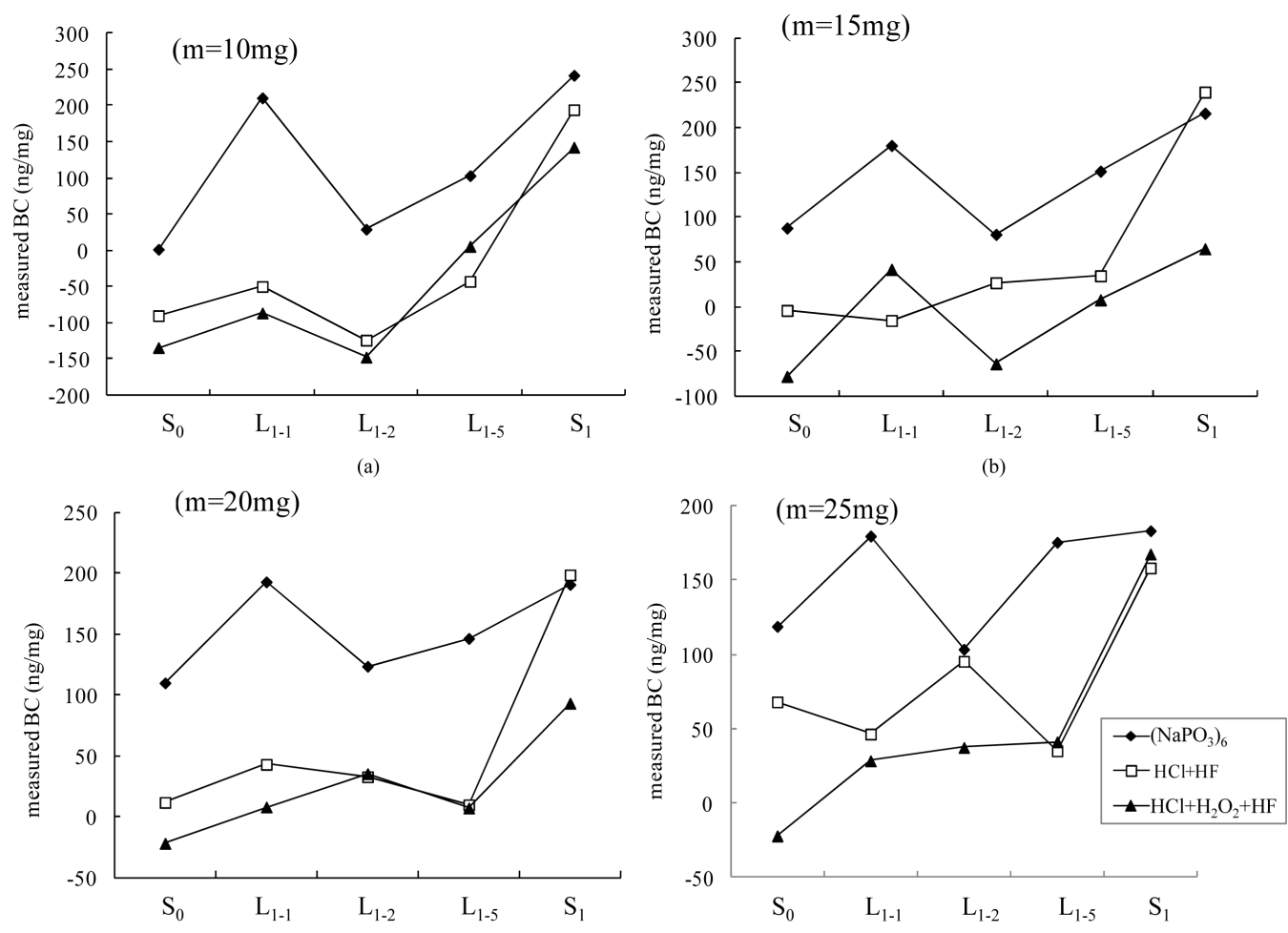

(c)

(d)

Figure 4. Comparison between “( $\left(\mathrm{NaPO}_{3}\right)_{6}$ pretreatment” and "HF acid pretreatment” with and without OC removal, for different sample masses.

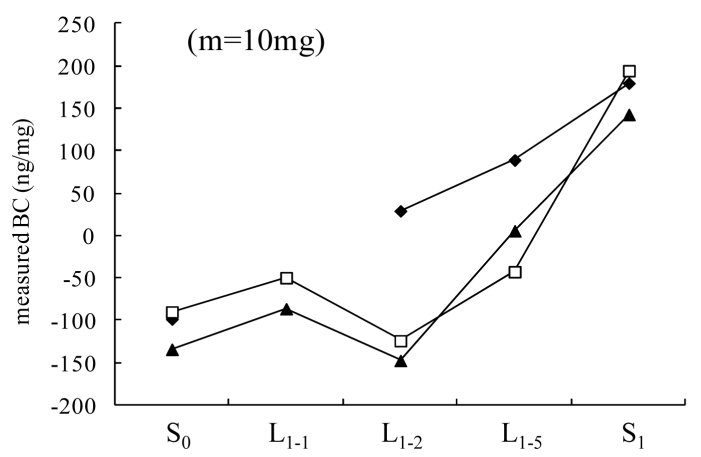

(a)

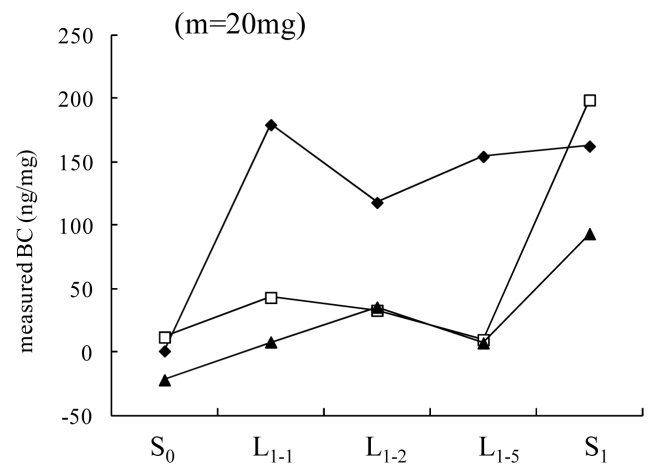

(c)

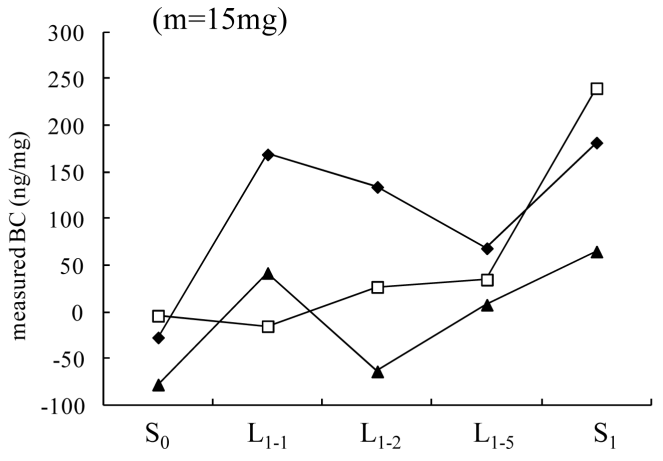

(b)

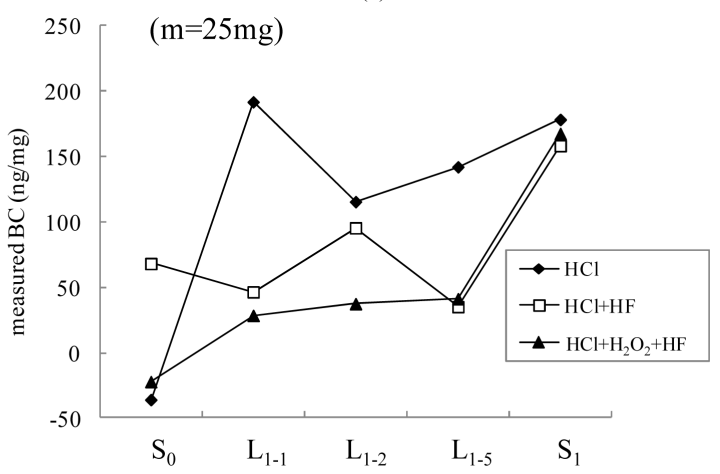

(d)

Figure 5. Comparison between "HCl pretreatment" and "HF pretreatment", with and without OC removal, for different sample masses. 
the $\mathrm{S}_{0}$ paleosol sample.

5) Comparison between " $\left(\mathrm{NaPO}_{3}\right)_{6}$ pretreatment" and " $\mathrm{H}_{2} \mathrm{O}_{2}$ pretreatment"

Figure 6 shows that in as many as $60 \%$ of the cases, $\mathrm{BC}$ results using the $\mathrm{H}_{2} \mathrm{O}_{2}$ procedure are higher than those using procedure 1 , although the $\mathrm{BC}$ results for the $\mathrm{S}_{0}$ and $\mathrm{L}_{1-1}$ samples using procedure 3 are lower than when using procedure 1 .

6) Comparison between " $\mathrm{H}_{2} \mathrm{O}_{2}+\mathrm{HCl}$ pretreatment" and " $\mathrm{H}_{2} \mathrm{O}_{2}$ pretreatment"

Figure 7 shows that in most cases, the $\mathrm{BC}$ values obtained for the $\mathrm{L}_{1-1}, \mathrm{~L}_{1-2}$ and $\mathrm{L}_{1-5}$ samples after using procedure 5 (adding $\mathrm{H}_{2} \mathrm{O}_{2}+\mathrm{HCl}$ ) were higher than after using procedure 3 (adding $\mathrm{H}_{2} \mathrm{O}_{2}$ ).

7) Comparison between " $\mathrm{H}_{2} \mathrm{O}_{2}+\mathrm{HCl}$ pretreatment" and " $\mathrm{HCl}+\mathrm{H}_{2} \mathrm{O}_{2}$ pretreatment"

To analyze the possible effect of the sequential order of $\mathrm{H}_{2} \mathrm{O}_{2}$ and $\mathrm{HCl}$ pretreatments, the $\mathrm{BC}$ results after the $\mathrm{H}_{2} \mathrm{O}_{2}+\mathrm{HCl}$ pretreatment were compared with those after the $\mathrm{HCl}+\mathrm{H}_{2} \mathrm{O}_{2}$ pretreatment. Figure 8 shows that these results are similar.

We may summarize the above results to state that an $\mathrm{H}_{2} \mathrm{O}_{2}$ pretreatment may usually result in a positive bias in $\mathrm{BC}$ measurement; while acid pretreatments, especially HF pretreatment, may lead to a negative bias on the BC measurement.

\subsubsection{Results of BC Measurement Allowing for a Possible Change in Mineral Optical Properties after Heating}

\section{1) Trends of optical attenuation (ATN) of different samples before and after heat treatment}

Figure 9 and Figure 10 show that for all samples, $A T N$ at $880 \mathrm{~nm}$ before and after heating treatment increases linearly with sample mass, and the analyses of samples of the same material using different pretreatments have similar trends, although there may be some very small differences. In Figure 9, the intercept of the regression lines before sample filter heating is close to zero, while Figure 10 shows that after heat treatment, the intercept may be greater or smaller than zero. The difference of ATN measurements before and after heat treatment may be due to the change of mineral optical properties during the firing process, and this change may also be the reason why the intercept of $\triangle A T N$ is not zero.

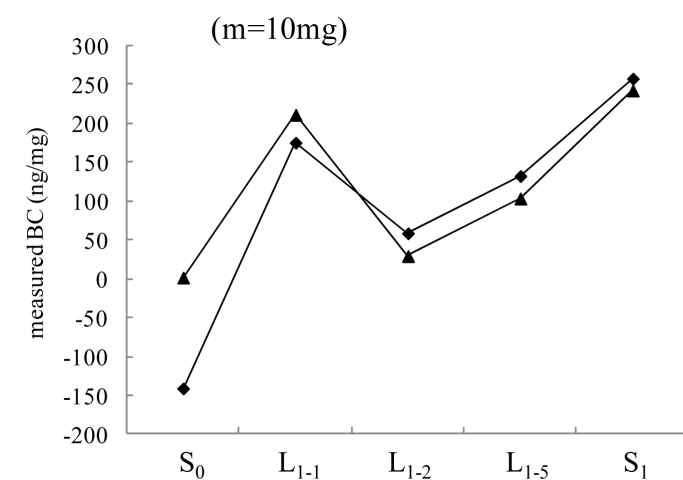

(a)

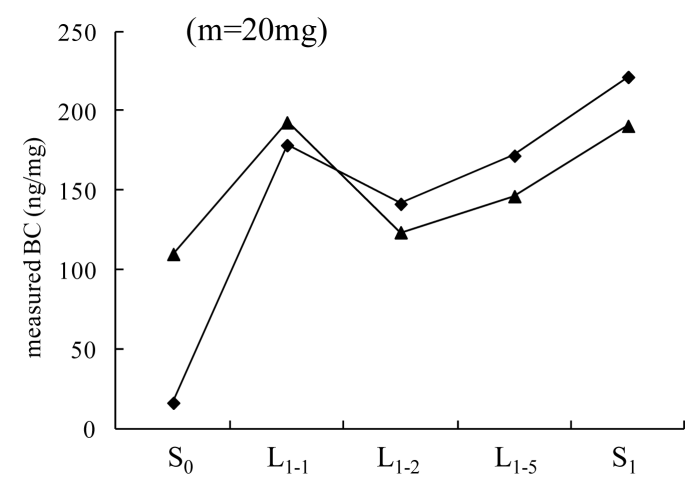

(c)

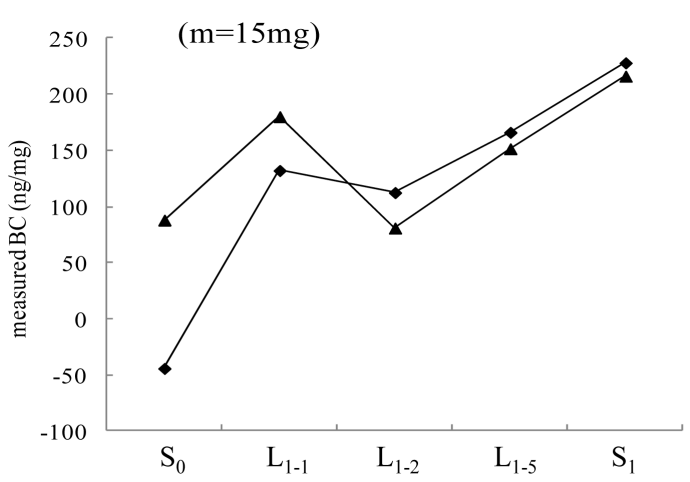

(b)

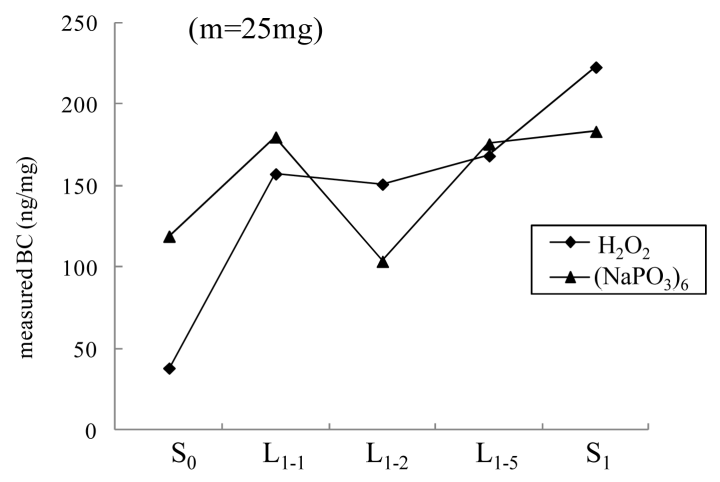

(d)

Figure 6. Comparison between "( $\left(\mathrm{NaPO}_{3}\right)_{6}$ pretreatment" and " $\mathrm{H}_{2} \mathrm{O}_{2}$ pretreatment", for different sample masses. 

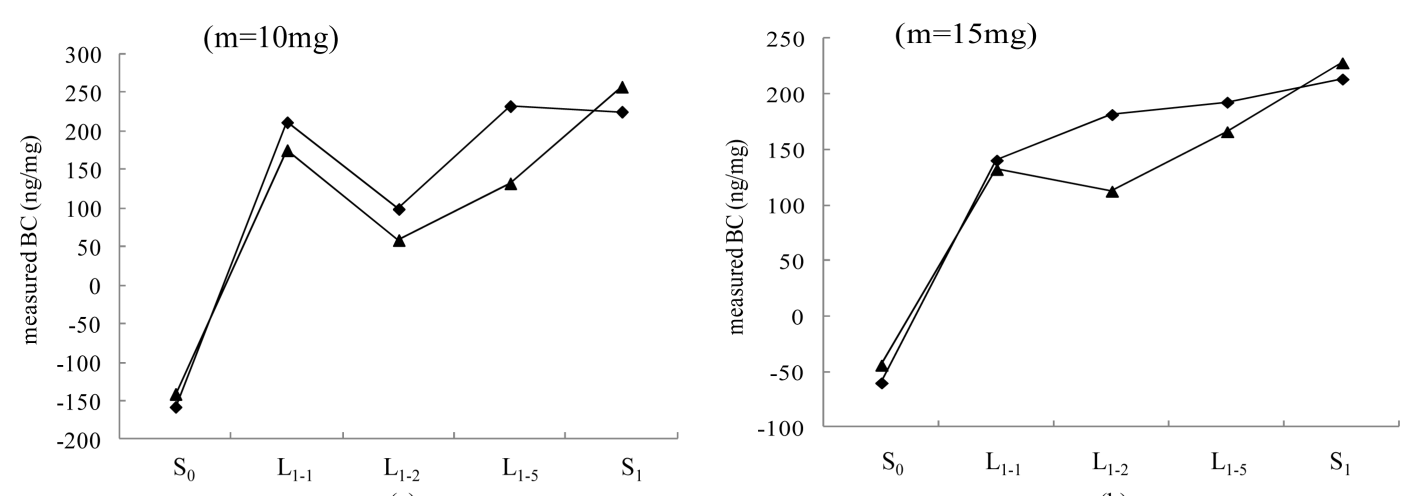

(a)

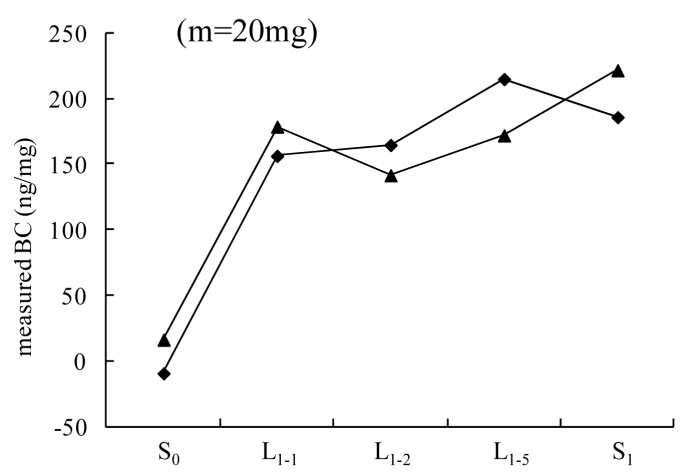

(c)

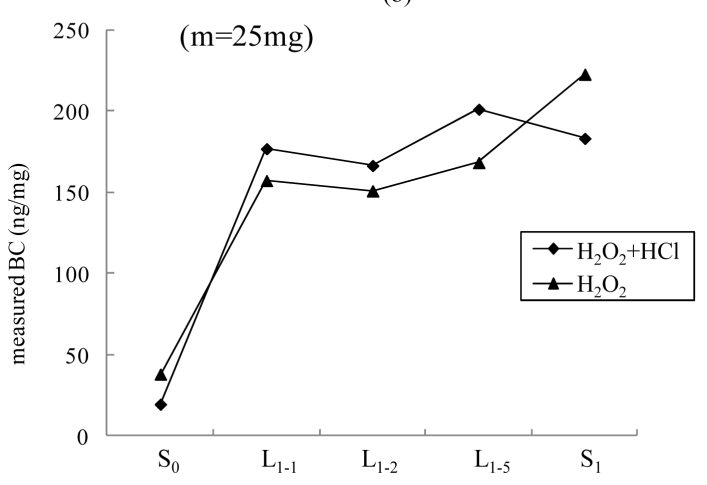

(d)

Figure 7. Comparison between " $\mathrm{H}_{2} \mathrm{O}_{2}+\mathrm{HCl}$ pretreatment" and " $\mathrm{H}_{2} \mathrm{O}_{2}$ pretreatment" at different mass levels.

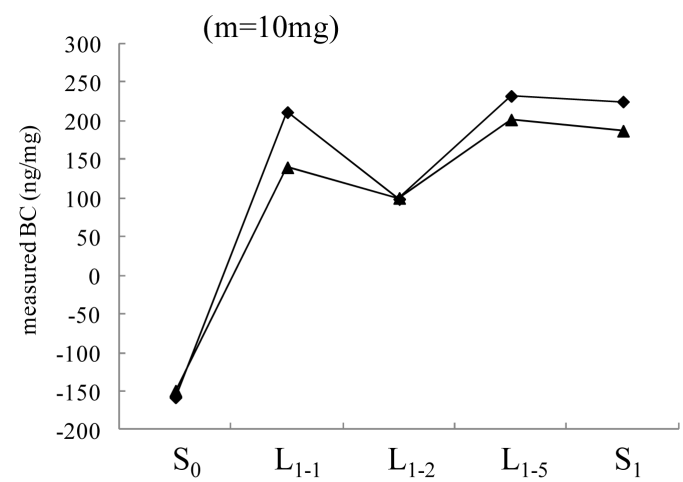

(a)

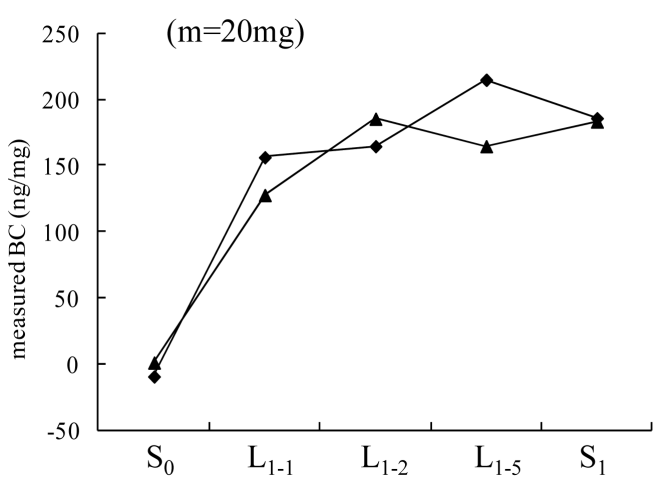

(c)

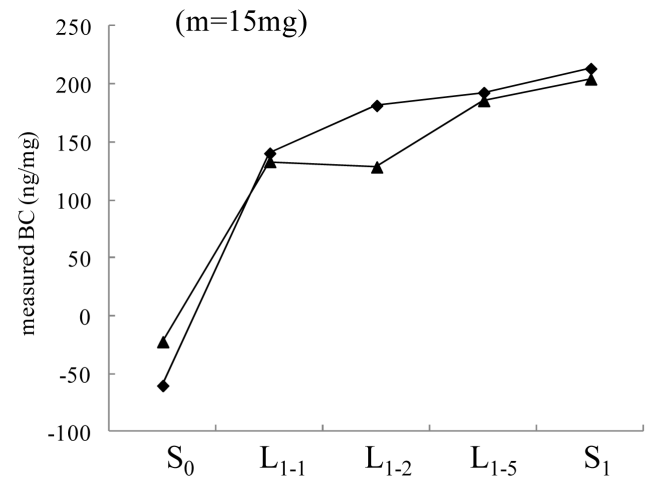

(b)

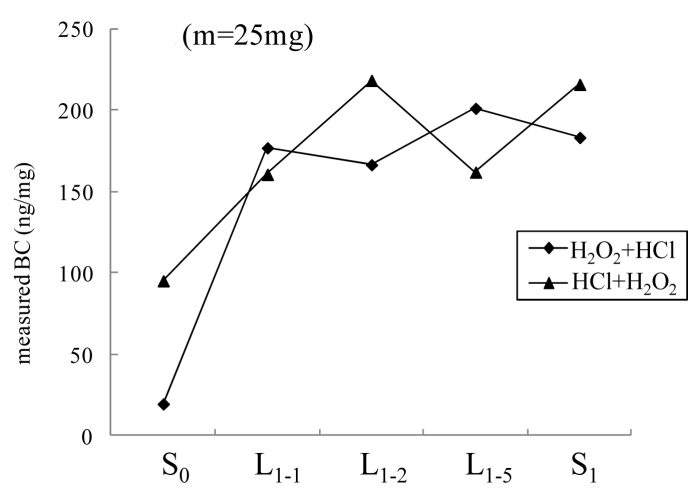

(d)

Figure 8. Comparison between " $\mathrm{H}_{2} \mathrm{O}_{2}+\mathrm{HCl}$ pretreatment" and " $\mathrm{HCl}+\mathrm{H}_{2} \mathrm{O}_{2}$ pretreatment" for different sample masses. 

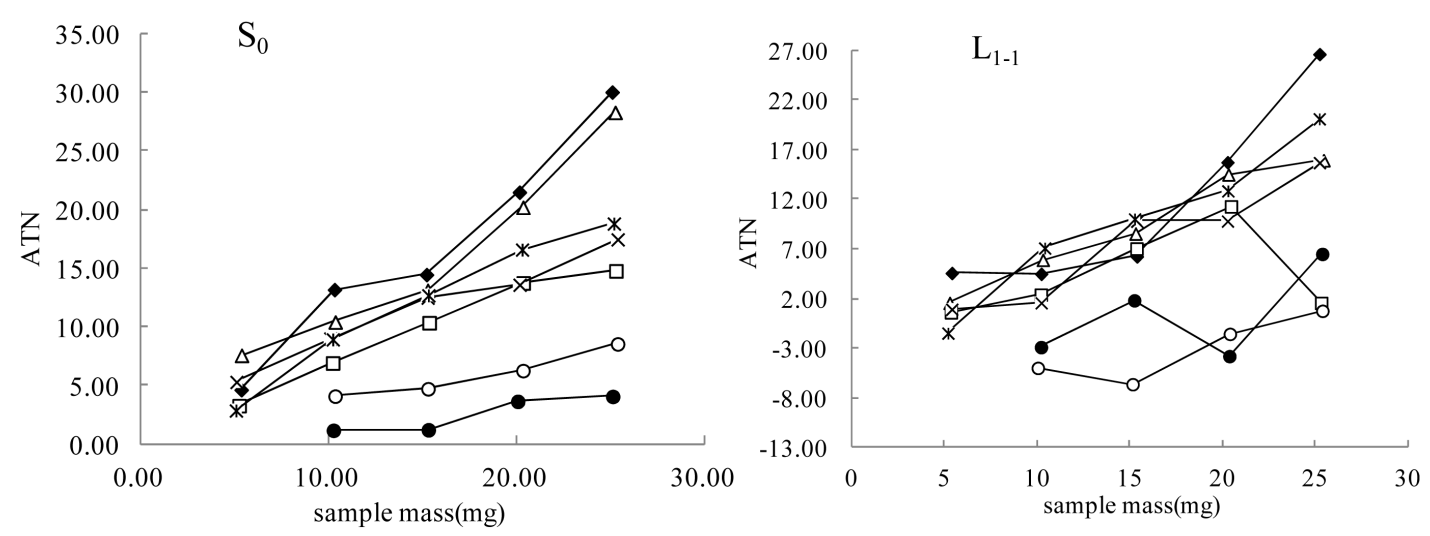

(a)

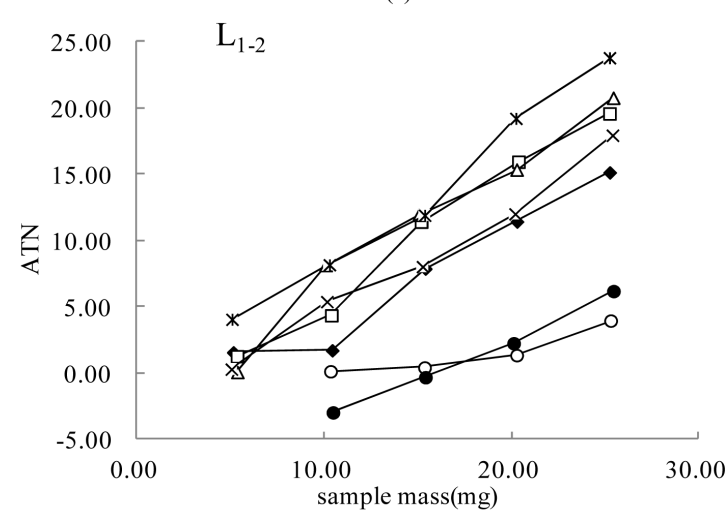

(c)

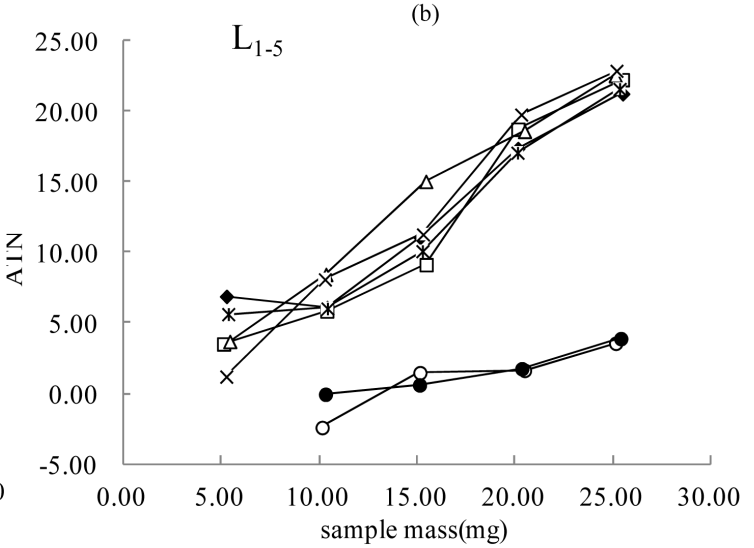

(d)

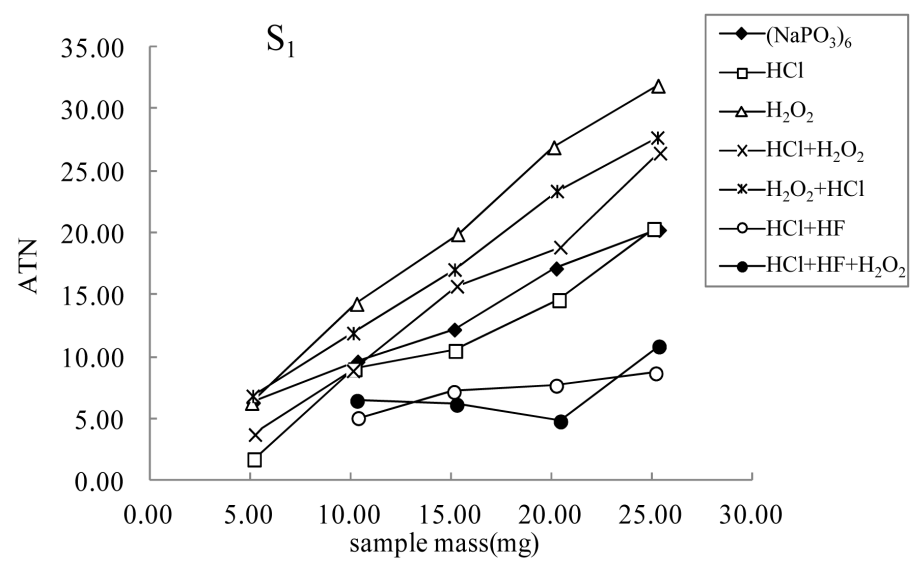

(e)

Figure 9. Trends in ATN of different samples before heat treatment.

\section{2) The $\triangle A T N$ results and the determination of $B C$ content}

The process of heating the sample filter to a high temperature may change the absorption of light at $880 \mathrm{~nm}$

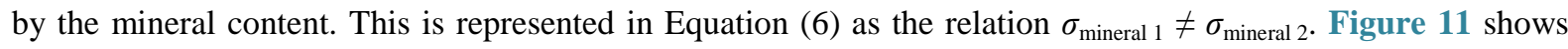
the $\triangle A T N$ results of all samples measured using light of $880 \mathrm{~nm}$ wavelength.

The relationship between $\triangle A T N$ and sample mass, shown in Figure 11, is important for understanding the physical significance of the measured $\mathrm{BC}$ value. It was found that $\triangle A T N$ of all pretreatment procedures varied linearly with sample mass for a given sample. For each sample, the intercepts of $\triangle A T N$ results of different samples may be positive or negative (Figure 11).

Figure 10 suggests that the Equation (4) can be rewritten: 


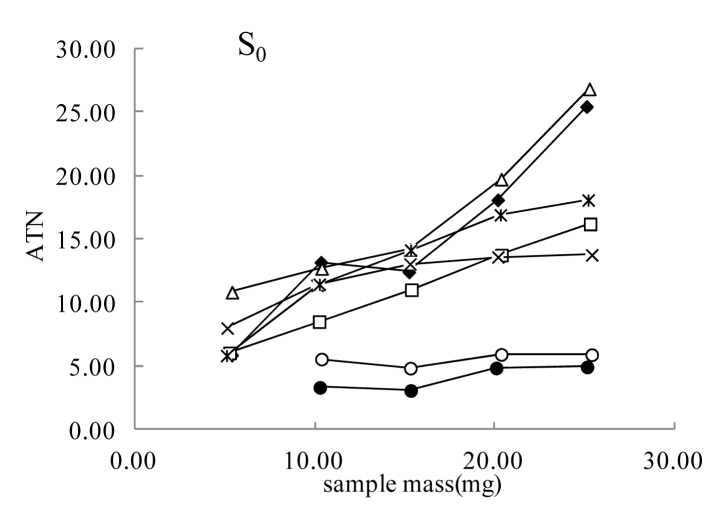

(a)

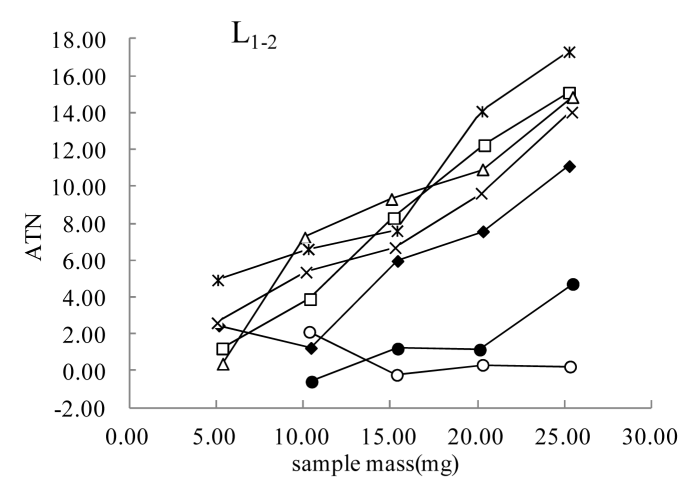

(c)

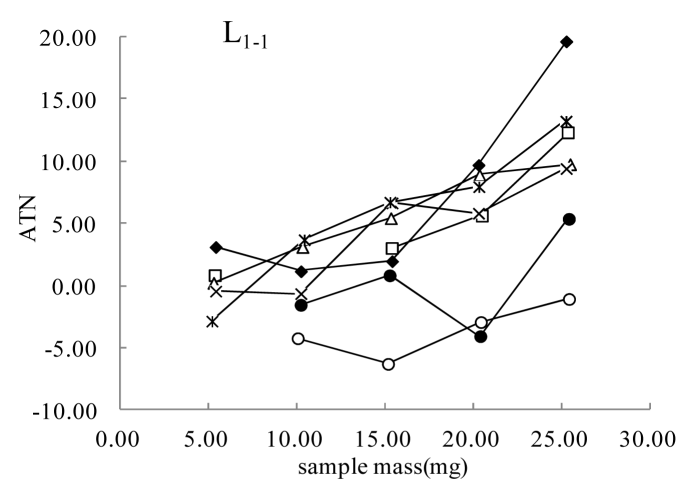

(b)

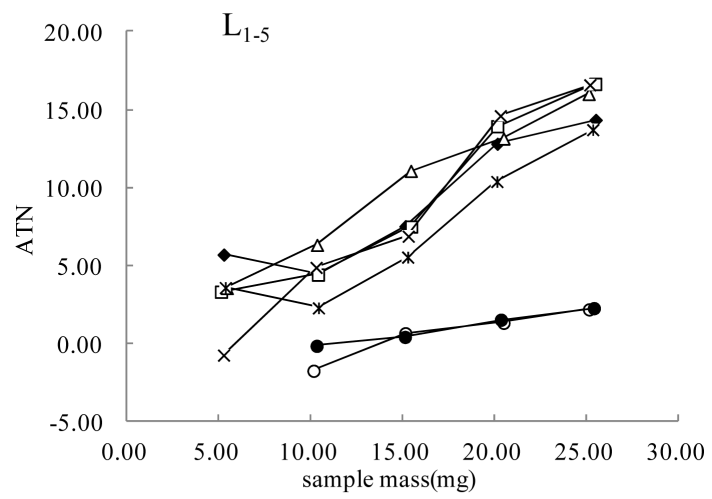

(d)

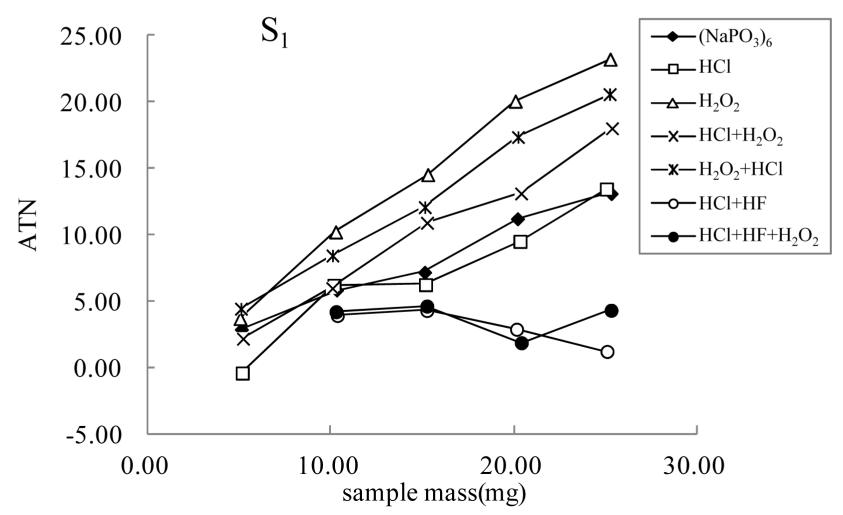

(e)

Figure 10. Trends in $A T N$ of different samples after heat treatment.

$$
A T N_{2}=\sigma_{\text {mineral } 2} \times[\text { mineral }]+\mathrm{C}
$$

where the intercept $\mathrm{C}$ of the regression lines is a constant, which can represent the effect of heating to the optical absorption of the sample filter.

Therefore, the equation (6) is rewritten as the following

$$
\triangle A T N=m \times\left(\sigma_{\mathrm{BC}} \times a+\Delta \sigma_{\text {mineral }} \times b\right)-\mathrm{C}
$$

Let $P$ represents the slope $\sigma_{\mathrm{BC}} \times a$. Then, the BC content can be gotten from the formula $a=P / \sigma_{\mathrm{BC}}$.

The equation describes results shown in Figure 11. It is noticed that there was good relationship between the sample mass and $\triangle A T N$, and the regression lines for the different procedures are nearly parallel in most cases (Figure 11). The slope of the regression lines for the HF pretreatments is slightly smaller than that for other procedures (Figure 11(a), Figure 11(b), Figure 11(d)), implying a possible tiny bias caused by $\Delta \sigma_{\text {mineral }}$ in other 


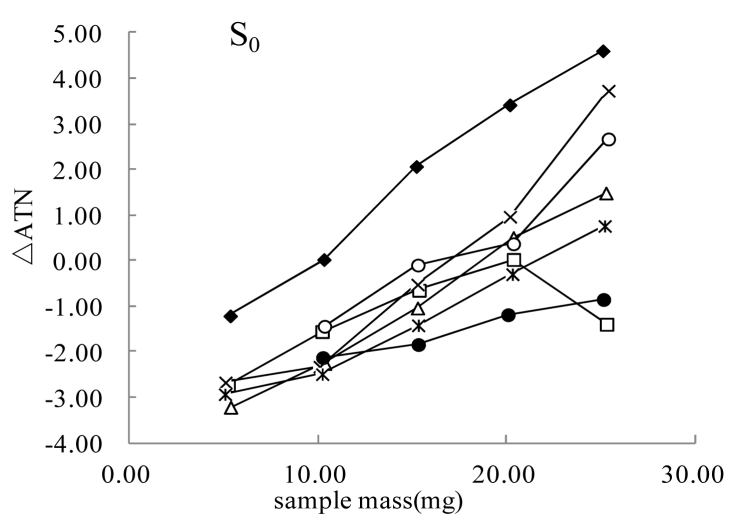

(a)

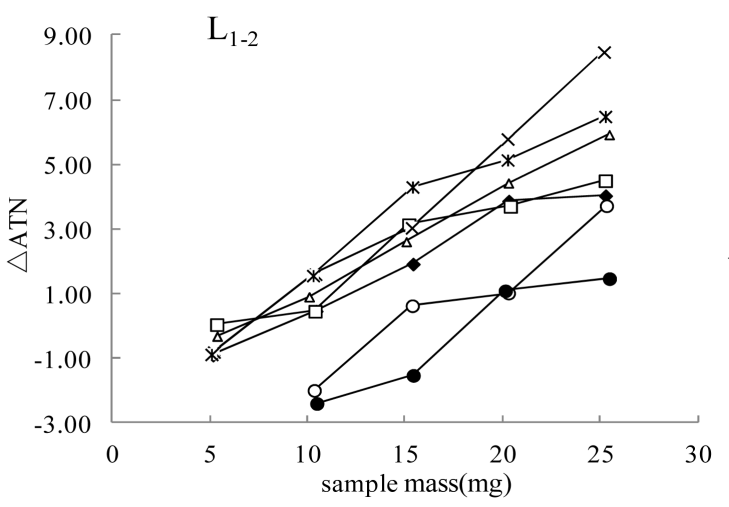

(c)

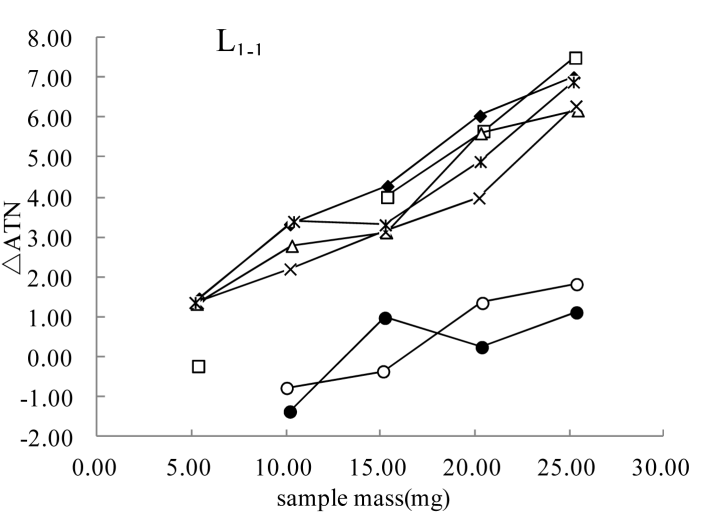

(b)

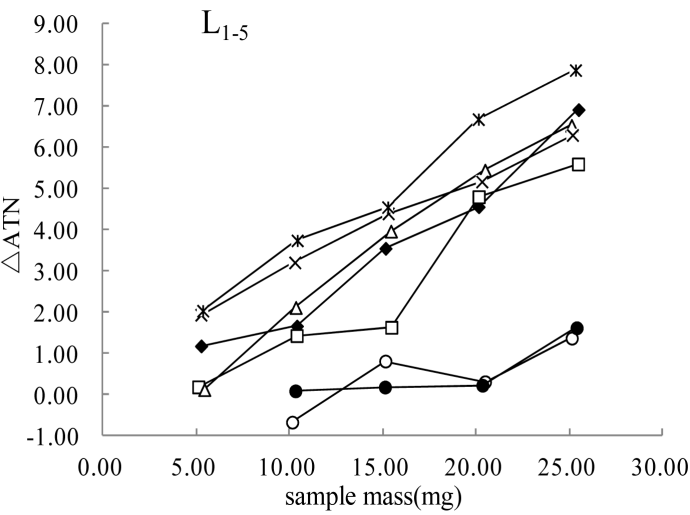

(d)

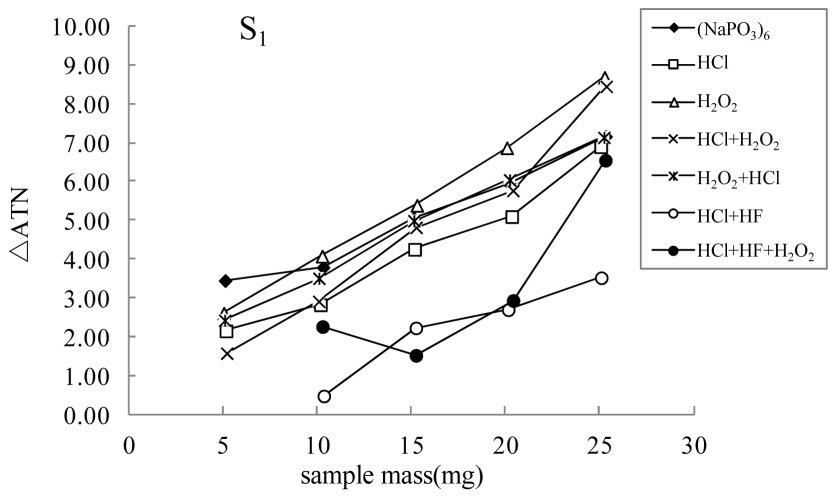

(e)

\section{Figure 11. The changes of $\triangle A T N$ measured at $880 \mathrm{~nm}$ as a function of sample mass.}

pretreatment procedures or a possible tiny negative bias caused by HF pretreatment procedures. It is because no minerals but BC were left on the quartz-fiber filter in HF pretreatments. Therefore, it can be concluded that $\Delta \sigma_{\text {mineral }}$ is low in most cases (i.e., $\Delta \sigma_{\text {mineral }} \approx 0$ ) and can be neglected for the measurement of $\mathrm{BC}$ content on 880-nm wavelength light.

\section{3) Comparison of BC contents of various pretreatments}

In order to eliminate the impact of minerals on BC concentration, the slope of $\triangle A T N$ will be used to determine $\mathrm{BC}$ concentration, because the change in specific attenuation coefficient of minerals after heating is very tiny $\left(\Delta \sigma_{\text {mineral }} \approx 0\right)$. The result is shown in Figure 12 .

It may be concluded that the $\left(\mathrm{NaPO}_{3}\right)_{6}$ pretreatment is a relatively simplified procedure which does not materially change the properties of the samples. In the $\left(\mathrm{NaPO}_{3}\right)_{6}$ pretreatment (Figure 12), the resultant $\mathrm{BC}$ concentration of loess samples estimated by using the slope of Equation (9) varies between $0.012 \%-0.025 \%$. This is 
the same order of magnitude as the $0.01 \%-0.054 \%$ result of Han et al. using the TOR method [29], but less than the average content $0.124 \%$ of the same study area published by Wang et al. using a chemical method [41].

When the sample mass is at the $200 \mathrm{mg}$ level, BC values obtained using HF pretreatment (with and without OC removal) estimated by Equation (6), have the same order of magnitude as those obtained using other pretreatment methods, estimated by the slope of Equation (9). Some quartz-fiber filters of $200 \mathrm{mg}$ sample mass cannot be measured because these filters are too thick for the 880 -nm transmitted light. This suggests that samples of mass 50 - 150 mg may be suitable for BC measurement using the OT-21 optical method after HF pretreatment. However, Figure 11 shows that the intercept of $\triangle A T N$ regression lines for most samples with HF pretreatment were not zero but negative. It is strongly suggested that HF pretreatment may underestimate the BC content, the HF pretreatment may be not an appropriate method to determine $\mathrm{BC}$ even though the effect of mineral species is low.

\section{4) Comparison of the intercepts of $\triangle A T N$ lines of various pretreatments}

Most of the values of the $\triangle A T N$ intercepts after different pretreatment procedures are negative, and the trends are also similar. However, Figure 13 shows that these values differ for different pretreatments of the same sample. The reason may be that the effect of different solvents on a sample may differ, and the absorption of $880 \mathrm{~nm}$ light by the mineral content of the sample may also be changed.

\section{Discussion}

\subsection{The Influence of Mineral Change}

Hansen et al. had assumed that the optical properties of the mineral content were not changed by the heating process [39]; and consequently the BC concentration could be calculated by the subtraction of results measured before and after heating. However, Figure 11 indicates that the results obtained in our work show that there was an intercept for the measurement of $\triangle A T N$ as a function of sample mass for all samples, under the assumption that the change in Specific Attenuation Coefficient of the mineral content is small $\left(\Delta \sigma_{\text {mineral }} \approx 0\right)$. This intercept will lead a positive or negative bias for $\mathrm{BC}$ measurement. Consequently, the analysis shows that the regression slope between $\triangle A T N$ and sample mass is the optimum means to determine the $\mathrm{BC}$ content of loess and sediment samples.

There may be a possible influence of some minerals on the results after different pretreatments, except after HF pretreatment (see Figure 13). It is therefore not reasonable to compare different pretreatment processes of a sample, even if the change of attenuation coefficient of the minerals is neglected $\left(\Delta \sigma_{\text {mineral }} \approx 0\right)$.

\subsection{Acid and Oxidation Pretreatment}

Compared with the $\left(\mathrm{NaPO}_{3}\right)_{6}$ pretreatment, $\mathrm{H}_{2} \mathrm{O}_{2}$ pretreatment may usually result in a positive bias in the $\mathrm{BC}$ determination by according to Equation (7) based on the assumption [39]. $\mathrm{HCl}$ acid pretreatments may lead to a negative bias of the $\mathrm{BC}$ result.

In the HF pretreatment process, some $\mathrm{BC}$ particles may be lost during the centrifugation and rinsing procedures, leading to an underestimation of BC. It was noticed that some of the ATN results before heated are negative for the HF pretreatment (see Figure 9). It may be because the residues of HF react with the quartz of the filter and thin the sample filter to lead that the intensity of transmission of light passing through the sample filter (I) may be higher than that passing through the blank filter.

\section{Conclusions}

An analysis method based on optical transmission using the OT-21 instrument was developed to measure the BC content of sediment samples.

1) Our progress was the improvement of optical method for BC measurement of dust aerosol samples. An experimental procedure for the BC optical measurement was developed in this study. Pretreated samples were added to de-ionized water and collected on quartz fiber filters. The optical attenuation of this filter was then measured. The subtraction $\triangle A T N$ of the two measured attenuation values-before and after the sample filters were heated at $850^{\circ} \mathrm{C}$ for 3 hours - was used to determine the BC concentration.

2) Various pretreatment processes of the loess samples were studied. The variations of measured BC in the loess 


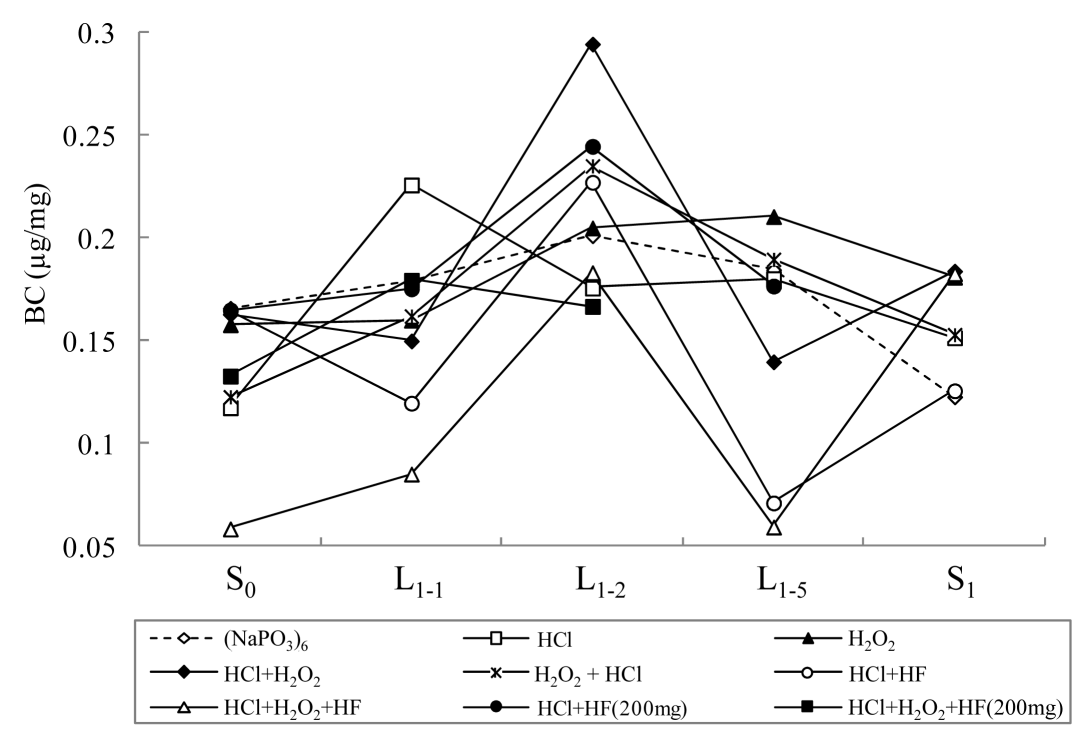

Figure 12. Variation of BC content result after different pretreatment procedures.

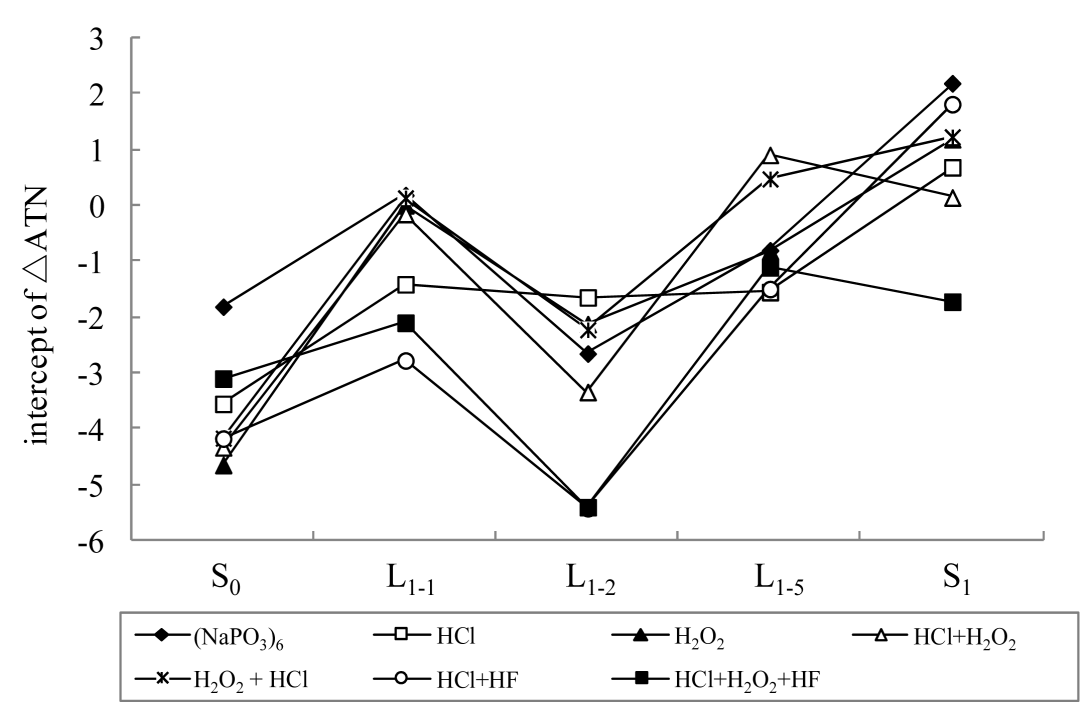

Figure 13. Intercept of the $\triangle A T N$ lines after different pretreatment procedures.

section are similar for all the pretreatments and the BC value of different samples was comparable if the samples were pretreated by the same procedure. The $\left(\mathrm{NaPO}_{3}\right)_{6}$ pretreatment is the simplest and best method for the $\mathrm{BC}$ optical measurement.

3) $\triangle A T N$ was always linear with sample mass for all pretreatment procedures. The slope of the regression line of $\triangle A T N$ with sample mass can be interpreted in terms of the BC concentration. Thus, using this slope to determine the BC concentration is the best optical measurement method.

4) Replicate analyses of BC for loess samples showed a deviation less than $5.6 \%$.

\section{Acknowledgements}

We would like to thank Liu Yuan and Lu Haiyan for technical assistance with the OT-21 instrument, Ning Bo for sampling, Wang Xu for useful discussion, Gu Zhaoyan and Xu Bing for providing the pretreatment laboratory, respectively. We also particularly acknowledge Tony Hansen for his important suggestions and the revision in English grammar. This work is financially supported by projects 411,721,158 and 40,772,212 of the Na- 
tional Natural Science Foundation of China, the Knowledge Innovation Program of the Chinese Academy of Sciences (Grant No. 241KZCX2-YW-Q1-03) and 973 Program (2010CB950200) of the National Basic Research Program of China.

\section{References}

[1] Ahmed, T., Dutkiewicz, V.A. and Shareef, A. (2009) Measurement of Black Carbon (BC) by an Optical Method and a thermal-Optical Method: Intercomparison for Four Sites. Atmospheric Environment, 43, 6305-6311. http://dx.doi.org/10.1016/j.atmosenv.2009.09.031

[2] Poot, A., Quik, J.T.K., Veld, H. and Koelmans, A.A. (2009) Quantification Methods of Black Carbon: Comparison of Rock-Eval Analysis with Traditional Methods. Journal of Chromatography A, 1216, 613-622. http://dx.doi.org/10.1016/j.chroma.2008.08.011

[3] Masiello, C.A. and Druffel, E.R.M. (1998) Black Carbon in Deep-Sea Sediments. Science, 280, 1911-1913. http://dx.doi.org/10.1126/science.280.5371.1911

[4] Wang, G.C., Bai, J.H., Kong, Q.X. and Emilenko, A. (2005) Black Carbon Particles in the Urban Atmosphere in Beijing. Advances in Atmospheric Sciences, 22, 640-646. http://dx.doi.org/10.1007/BF02918707

[5] Preston, C.M. and Schmidt, M.W.I. (2006) Black (Pyrogenic) Carbon: A Synthesis of Current Knowledge and Uncertainties with Special Consideration of Boreal Regions. Biogeosciences, 3, 397-420. http://dx.doi.org/10.5194/bg-3-397-2006

[6] Hsieh, Y.P. and Bugna, G.C. (2008) Analysis of Black Carbon in Sediments and Soils Using Multi-Element Scanning Thermal Analysis (MESTA). Organic Geochemistry, 39, 1562-1571. http://dx.doi.org/10.1016/j.orggeochem.2008.07.015

[7] Gelinas, Y., Prentice, K.M., Bladock, J.A. and Hedges, J.I. (2001) An Improved Thermal Oxidation Method for the Quantification of Soot/Graphitic Black Carbon in Sediments and Soils. Environmental Science \& Technology, 35, 3519-3525. http://dx.doi.org/10.1021/es010504c

[8] Elmquist, M., Gustafsson, Ö. and Andersson, P. (2004) Quantification of Sedimentary Black Carbon Using the Chemothermal Oxidation Method: An Evaluation of Ex Situ Pretreatments and Standard Additions Approaches. Limnology and Oceanography: Methods, 2, 417-427. http://dx.doi.org/10.4319/lom.2004.2.417

[9] Schmidt, M.W.I. and Noack, A.G. (2000) Black Carbon in Soils and Sediments: Analysis, Distribution, Implications, and Current Challenges. Global Biogeochemical Cycles, 14, 777-793. http://dx.doi.org/10.1029/1999GB001208

[10] Bird, M.I.J. and Cali, A. (1998) A Million-Year Record of Fire in Sub-Saharan Africa. Nature, 394, 767-769. http://dx.doi.org/10.1038/29507

[11] Lim, B. and Cachier, H. (1996) Determination of Black Carbon by Chemical Oxidation and Thermal Treatment in Recent Marine and Lake Sediments and Cretaceous-Tertiary Clays. Chemical Geology, 131, 143-154. http://dx.doi.org/10.1016/0009-2541(96)00031-9

[12] Muri, G., Cermelj, B., Faganeli, J. and Brancelj, A. (2002) Black Carbon in Slovenian Alpine Lacustrine Sediments. Chemosphere, 46, 1225-1234. http://dx.doi.org/10.1016/S0045-6535(01)00295-8

[13] Seiler, W. and Crutzen, P.J. (1980) Estimates of Gross and Net Fluxes of Carbon between the Biosphere and the Atmosphere from Biomass Burning. Climatic Change, 2, 207-247. http://dx.doi.org/10.1007/BF00137988

[14] Kuhlbusch, T.A.J. and Crutzen, P.J. (1995) Toward a Global Estimate of Black Carbon in Residues of Vegetation Fires Representing a Sink of Atmospheric $\mathrm{CO}_{2}$ and a Source of $\mathrm{O}_{2}$. Global Biogeochemical Cycles, 9, 491-501. http://dx.doi.org/10.1029/95GB02742

[15] Trumbore, S.E., Chadwick, O.A. and Amundson, R. (1996) Rapid Exchange between Soil Carbon and Atmospheric Carbon Dioxide Driven by Temperature Change. Science, 272, 392-396. http://dx.doi.org/10.1126/science.272.5260.393

[16] Middelburg, J.J., Nieuwenhuize, J. and van Breugel, P. (1999) Black Carbon in Marine Sediments. Marine Chemistry, 65, 245-252. http://dx.doi.org/10.1016/S0304-4203(99)00005-5

[17] Simpson, M.J. and Hatcher, P.G. (2004) Overestimates of Black Carbon in Soils and Sediments. Naturwissenschaften, 91, 436-440. http://dx.doi.org/10.1007/s00114-004-0550-8

[18] Sun, X.S., Peng, P.A., Song, J.Z., Zhang, G. and Hu, J.F. (2008) Sedimentary Record of Black Carbon in the Pearl River Estuary and Adjacent Northern South China Sea. Applied Geochemistry, 23, 3464-3472. http://dx.doi.org/10.1016/j.apgeochem.2008.08.006

[19] Schmidt, M.W.I., Masiello, C.A. and Skjemstad, J.O. (2003) Final Recommendations for Reference Materials in Black Carbon Analysis. Eos, Transactions American Geophysical Union, 52, 582-583.

http://dx.doi.org/10.1029/2003EO520006 
[20] Schmidt, M.W.I., Skjemstad, J.O., Czimczik, C.I., Glaser, B., Prentice, K.M., Gelinas, Y. and Kuhlbusch, T.A.J. (2001) Comparative Analysis of Blank Carbon in Soils. Global Biogeochemical Cycles, 15, 163-167. http://dx.doi.org/10.1029/2000GB001284

[21] Gustafsson, O., Bucheli, T.D., Kukulska, Z., Andersson, M., Largeau, C., Rouzaud, J.-N., et al. (2001) Evaluation of a Protocol for the Quantification of Black Carbon in Sediments. Global Biogeochemical Cycles, 15, 881-890. http://dx.doi.org/10.1029/2000GB001380

[22] Hammes, K., Schmidt, M.W.I., Smernik, R.J., Currie, L.A., Ball, W.P., Nguyen, T.H., et al. (2007) Comparison of Quantification Methods to Measure Fire-Derived (Black/Elemental) Carbon in Soils and Sediments Using Reference Materials from Soil, Water, Sediment and the Atmosphere. Global Biogeochemical Cycles, 21. http://dx.doi.org/10.1029/2006gb002914

[23] Nguyen, T.H., Brown, R.A. and Ball, W.P. (2004) An Evaluation of Thermal Resistance as a Measure of Black Carbon Content in Diesel Soot, Wood Char, and Sediment. Organic Geochemistry, 35, 217-234. http://dx.doi.org/10.1016/j.orggeochem.2003.09.005

[24] Gustafsson, O., Haghseta, F., Chan, C., Macfarlane, J. and Gschwend, P.M. (1997) Quantification of the Dilute Sedimentary Soot Phase: Implications for PAH Speciation and Bioavailability. Environmental Science \& Technology, 31, 203-209. http://dx.doi.org/10.1021/es960317s

[25] Allen, G.A., Lawrence, J. and Koutrakis, P. (1998) Field Validation of a Semi-Continuous Method for Aerosol Black Carbon (Aethalometer) and Temporal Patterns of Summertime Hourly Black Carbon Measurements in Southwestern PA. Atmospheric Environment, 33, 817-823. http://dx.doi.org/10.1016/S1352-2310(98)00142-3

[26] Chow, J.C., Watson, J.G., Pritchett, L.C., Pierson, W.R., Frazier, C.A. and Purcell, R.G. (1993) The Dri Thermal/Optical Reflectance Carbon Analysis System: Description, Evaluation and Applications in US Air Quality Studies. Atmospheric Environment, 27, 1185-1201. http://dx.doi.org/10.1016/0960-1686(93)90245-T

[27] Chow, J.C., Watson, J.G., Chen, L.W.A., Arnott, W.P. and Moosmuller, H. (2004) Equivalence of Elemental Carbon by Thermal/Optical Reflectance and Transmittance with Different Temperature Protocols. Environmental Science Technology, 38, 4414-4422.

[28] Watson, J.G., Chow, J.C. and Chen, L.W.A. (2005) Summary of Organic and Elemental Carbon/Black Carbon Analysis Methods and Intercomparisons. Aerosol and Air Quality Research, 5, 65-102.

[29] Han, Y.M., Cao, J.J., An, Z.S., Chow, J.C., Watson, J.G., Jin, Z.D., Fung, K. and Liu, S.X. (2007) Evaluation of the Thermal/Optical Reflectance Method for Quantification of Elemental Carbon in Sediments. Chemosphere, 69, 526-533. http://dx.doi.org/10.1016/j.chemosphere.2007.03.035

[30] Han, Y.M., Cao, J.J., Chow, J.C., Watson, J.G., An, Z.S., Jin, Z.D., Fung, K. and Liu, S.X. (2007) Evaluation of the Thermal/Optical Reflectance Method for Discrimination between Char- and Soot-EC. Chemosphere, 69, 569-574. http://dx.doi.org/10.1016/j.chemosphere.2007.03.024

[31] Han, Y.M., Han, Z.W., Cao, J.J., Chow, J.C., Watson, J.G., An, Z.S., Liu, S.X. and Zhang, R.J. (2008) Distribution and Origin of Carbonaceous Aerosol over a Rural High-Mountain Lake Area, Northern China and Its Transport Significance. Atmospheric Environment, 42, 2405-2414. http://dx.doi.org/10.1016/j.atmosenv.2007.12.020

[32] Han, Y.M., Cao, J.J., Posmentier, E.S., Chow, J.C., Watson, J.G., Fung, K.K., Jin, Z.D., Liu, S.X. and An, Z.S. (2008) The Effect of Acidification on the Determination of Elemental Carbon, Char-, and Soot-Elemental Carbon in Soils and Sediments. Chemosphere, 75, 92-99.

[33] Glaser, B., Haumaier, L., Guggenberger, G. and Zech, W. (1998) Black Carbon in Soils: The Use of Benzenecarboxylic Acids as Specific Markers. Organic Geochemistry, 29, 811-819. http://dx.doi.org/10.1016/S0146-6380(98)00194-6

[34] Qiu, J., Gao, R., Yang, Y.S., Yin, Y.F., Ma, H.L. and Li, Y.F. (2009) Advances on Research of Black Carbon in Soil. Journal of Subtropical Resources and Environment, 4, 88-94. (In Chinese)

[35] Zhang, X.D., Liang, C., Ge, Y.P., Jiang, Y., Xie, H.T., He, H.B. and Wang, J. (2003) Roles of Black Carbon in the Biogeochemical Cycles of Soil Organic Carbon. Chinese Journal of Soil Science, 34, 349-355. (In Chinese)

[36] Currie, L.A., Benner, B.A., Kessler, J.D., Klindinst, D.B., Kloda, G.A., Marolf, J.V., Slater, J.F., Wise, S.A., Cachier, H., Cary, R., Chow, J.C., Watson, J., Druffel, E.R.M., Masiello, C.A., Eglinton, T.I., Pearson, A., Reddy, C.M., Gustafsson, O., Quinn, J.G., Hartmann, P.C., Hedges, J.I., Prentice, K.M., Kirchstetter, T.W., Novakov, T., Puxbaum, H. and Schmid, H.A. (2002) Critical Evaluation of Interlaboratory Data on Total, Elemental, and Isotopic Carbon in the Carbonaceous Particle Reference Material, NIST SRM 1649a. Journal of Research of the National Institute of Standards and Technology, 107, 279-298. http://dx.doi.org/10.6028/jres.107.022

[37] Han, Y.M., Cao, J.J., Chow, J.C., Watson, J.G., An, Z.S. and Liu, S.X. (2009) Elemental Carbon in Urban Soils and Road Dusts in Xi'an, China and Its Implication for Air Pollution. Atmospheric Environment, 43, 2464-2470. http://dx.doi.org/10.1016/j.atmosenv.2009.01.040

[38] Hansen, A.D.A., Rosen, H. and Novakov, T. (1984) The Aethalometer-An Instrument for the Real-Time Measure- 
ment of Optical Absorption by Aerosol Particles. Science of The Total Environment, 36, 191-196. http://dx.doi.org/10.1016/0048-9697(84)90265-1

[39] Hansen, A.D.A., Kapustin, V.N., Kopeikin, V.M., Gillette, D.A. and Bodhaine, B.A. (1993) Optical Absorption by Aerosol Black Carbon and Dust in Desert Region of Central Asia. Atmospheric Environment, 27, 2527-2531. http://dx.doi.org/10.1016/0960-1686(93)90025-T

[40] Liu, T.S. (1985) Loess and the Environment. Science Press, Beijing. (In Chinese)

[41] Wang, X., Peng, P.A. and Ding, Z.L. (2005) Black Carbon Records in Chinese Loess Plateau over the Last Two Glacial Cycles and Implications for Paleofires. Palaeogeography, Palaeoclimatology, Palaeoecology, 223, 9-19. http://dx.doi.org/10.1016/j.palaeo.2005.03.023

[42] Liu, J.Q , Chen, T.M., Nie, G.Y., Song, C.Y., Guo, Z.T., Li, K., Gao, S.J., Qiao, Y.L. and Ma, Z.B. (1994) Dating and Reconstruction of the High Resolution Time Series in the Weinan Loess Section of the Last 150 ka B.P. Quaternary Sciences, 3, 193-202. (In Chinese)

[43] Qin, X.G., Cai, B.G. and Liu, T.S. (2005) Loess Record of the Aerodynamic Environment in the East Asia Monsoon Area since 60000 before Present. Journal of Geophysical Research, 29, 1-16.

[44] Qin, X.Q., Mu, Y., Ning, B. and Yin, Z.Q. (2008) Climate Effect of Dust Aerosol in Southern Chinese Loess Plateau over the Last 140,000 Years. Geophysical Research Letters, 36, Article ID: L02707.

[45] Gundel, L.A., Dod, R.L., Rosen, H. and Novakov, T. (1984) The Relationship between Optical Attenuation and Black Carbon Concentration for Ambient and Source Particles. Science of the Total Environment, 36, 197-202. http://dx.doi.org/10.1016/0048-9697(84)90266-3 